\title{
Old and New Flavors of Flame (Furnace) Atomic Absorption Spectrometry
}

\author{
Amália Geiza Gama Dionísio, Amanda Maria Dantas de Jesus, Renata Stábile Amais, \\ George Luís Donati, Kelber dos Anjos Miranda, Marcelo Braga Bueno Guerra, \\ Joaquim Araújo Nóbrega, and Edenir Rodrigues Pereira-Filho
}

\begin{abstract}
Group of Applied Instrumental Analysis (GAIA), Department of Chemistry, Federal University of São Carlos (UFSCar), Rod. Washington Luiz, km 235, P. O. Box 676, 13565-905 São Carlos, SP, Brazil
\end{abstract}

Correspondence should be addressed to Edenir Rodrigues Pereira-Filho, erpf@ufscar.br

Received 20 May 2011; Accepted 4 August 2011

Academic Editor: A. M. Brouwer

Copyright (c) 2011 Amália Geiza Gama Dionísio et al. This is an open access article distributed under the Creative Commons Attribution License, which permits unrestricted use, distribution, and reproduction in any medium, provided the original work is properly cited.

This paper presents some recent applications of Flame Atomic Absorption Spectrometry (FAAS) to different matrices and samples. The time window selected was from 2006 up to March, 2011, and several aspects related to food, biological fluids, environmental, and technological samples analyses were reported and discussed. In addition, the chemometrics application for FAAS methods development was also taken into account, as well as the use of metal tube atomizers in air/acetylene flame. Preconcentration methods coupled to FAAS were discussed, and several approaches related to speciation, flotation, ionic liquids, among others were discussed. This paper can be interesting for researchers and FAAS users in order to see the state of the art of this technique.

\section{Introduction}

Flame Atomic Absorption Spectrometry (FAAS) is one of the most successfully implemented analytical techniques. Its main characteristics are the versatility and low cost (acquisition and operation). Several AAS approaches are presented in the literature, such as those using metal tube atomizers, hydride generation, and preconcentration procedures. The main objective of this paper is to present Flame and Flame Furnace AAS applications related to food analysis, fuels, biological fluids, environmental samples and technological materials, chemometrics, and preconcentration step. Several papers were organized from 2006 to March, 2011, and its main characteristics are reported and discussed.

\section{Applications to Specific Samples}

2.1. Food. Most developments in the searched period dealt with simplification of strategies for sample preparation, including slurries, preconcentration, and fractionation studies. Some authors also investigated improvements in instrument performance using either simple lab-made devices, such as Thermospray Flame Furnace AAS (TS-FF-AAS) or commercial instruments, such as High-Resolution Continuum Source FAAS (HR-CS-FAAS) and Fast Sequential FAAS (FS-FAAS). Some aspects of these developments will be highlighted with emphasis on practical approaches for obtaining fast analytical data and additional information applying proper tools for data treatment. The cited literature is not comprehensive, but represents relevant developments for improving and expanding the scope of food analysis.

Fast analytical data can be obtained by reducing the time spent in the conversion of solid samples to representative solutions which can be introduced by nebulization into the flame atomizer. Simple strategies can be based on the preparation of slurries or extractions assisted by ultrasound mechanical waves or microwave radiation. The feasibility of introduction of slurries prepared using ultrasound bath was demonstrated for determination of $\mathrm{Mn}$ in cassava leaves [1] and $\mathrm{Zn}$ in yogurt [2]. Both procedures used a $20 \mathrm{~min}$ sonication time, and determination was performed using conventional FAAS or HR-CS-FAAS, respectively. Bugallo et al. demonstrated the application of slurry technique for analysis of fish tissues by FAAS; however Fe was only accurately 
determined when the suspension was rapidly heated by microwave radiation (i.e., 15-30 s at 75-285 W) [3]. This is expected considering the strong association of $\mathrm{Fe}$ and $\mathrm{Al}$ with matrix components in biological samples. Emulsification was also successfully applied for determination of $\mathrm{Ca}, \mathrm{Fe}, \mathrm{Mg}$, $\mathrm{K}, \mathrm{Na}$, and $\mathrm{Zn}$ in egg samples by FAAS [4]. The preparation of the emulsion was carefully studied using different oily phases and surfactants. The best conditions are dependent on the element being determined. Two advantages of the developed method are the use of fewer reagents and the calibration using reference solutions prepared in water medium. Another simple procedure for analysis of a complex sample, in this case buffalo milk, was proposed by Pereira et al. using the dilution of the sample in water-soluble tertiary-amines medium [5]. Calcium, Mg, Mn, and $\mathrm{Zn}$ were further determined by FAAS, and no difficulties were caused by the fat content and particle size distribution of the emulsion. It should be mentioned that buffalo milk has about twice the amount of fats compared to cow milk.

Online sample digestion was proposed for determination of $\mathrm{Mn}$ and $\mathrm{Zn}$ in tea leaves [6]. The digestion was based on the electromagnetic-induced heating of a column made with polytetrafluoroethylene (PTFE) outer tube and seven compactly packed PTFE coil-coated Fe wires. Further determination was performed by FAAS, and sample throughput was $72 /$ h. Offline sample digestion based on photooxidation with ultraviolet radiation and $\mathrm{H}_{2} \mathrm{O}_{2}$ for 30 min was applied for decomposition of wine samples followed by determination of Fe and Mn by FAAS [7].

Nowadays there is also a trend towards getting information about chemical forms and fractions. In this sense, Pohl and associates have developed fractionation procedures using successive Solid Phase Extractions (SPEs) columns for determination of $\mathrm{Cu}, \mathrm{Fe}$, and $\mathrm{Mn}$ in freshly ripened honeys [8], Mn and $\mathrm{Zn}$ in beers [9, 10], Ca, Mg, Fe and $\mathrm{Zn}$ in ultrahigh temperature cow milks [11], and $\mathrm{Ca}$ and $\mathrm{Mg}$ [12] and $\mathrm{Fe}$ and $\mathrm{Zn} \mathrm{[13]} \mathrm{in} \mathrm{dietary} \mathrm{foods} \mathrm{and} \mathrm{beverage} \mathrm{products,} \mathrm{such} \mathrm{as}$ bee honeys, fruit juices, and tea infusions. All developed fractionation procedures used FAAS for analytes determination and generated information about chemical forms.

A thorough discussion about sample preparation strategies for determination of metals in food analysis using spectroanalytical methods was presented by Korn et al., and a careful reading of this review is highly recommended [14].

Improvements in sensitivity for FAAS were proposed using either simple instrumental strategies, such as the use of a thermospray flame furnace for determination of $\mathrm{Cd}$ and $\mathrm{Pb}$ in complementary foods during the breastfeeding period [15], or online preconcentration columns, such as a modified Amberlite XAD-2 column for determining Cd, Co, and $\mathrm{Ni}$ [16] or a modified polyurethane foam for determining $\mathrm{Cu}$ [17] in food samples.

The analytical capability of FAAS was also expanded for indirect determination of total I in milk [18]. Milk samples were digested using an alkaline ashing procedure. Then, a flow system was used for precipitating $\mathrm{I}^{-}$with $\mathrm{Ag}^{+}$and collecting the precipitate in a filter. Further, the precipitate was washed and dissolved by using diluted ammonia and thiosulfate solutions. Finally, Ag was determined by FAAS. Adopting this strategy, it was possible to circumvent one of the critical limitations of FAAS related to the determination of anions.

Another frequent limitation pointed out for FAAS is its monoelemental character. Notwithstanding, this aspect is being minimized using new instrumental arrangements. For instance, an FS-FAAS was used for the implementation of the internal standard technique for the direct determination of $\mathrm{Cu}$ in fruit juices [19]. Ferreira et al. demonstrated that the use of In as internal standard improved the accuracy and the repeatability for $\mathrm{Cu}$ determination in nondigested juice samples. Better performance for correcting matrix effects was also obtained when Co and In were used as reference elements for $\mathrm{Mn}$ and $\mathrm{Fe}$, respectively, in wine samples [20]. Additionally, Oliveira et al. demonstrated the application of HR-CS-FAAS for determination of macroand micronutrients in plant leaves [21, 22]. These authors exploited instrumental capabilities, such as wavelength integrated absorbance, molecular absorption bands, side pixel registration approach, least-squares background correction, and measurements at line wings, for making feasible the accurate and precise determination of macro- and micronutrients in foliar analysis.

2.2. Fuels. Fuel is any material that is capable of releasing energy and can be used to produce work. The automotive fuels most worldwide commercialized are gasoline, diesel, ethanol, and more recently biodiesel [23]. In the 1970s, during the first petrol crises, Brazil introduced the National Program of Alcohol (Programa Nacional do Álcool, Proálcool), and this fact has stimulated flex-fuel cars production and technological investments. As a consequence, nowadays most cars sold in Brazil are equipped with flexible fuel engines [24]. However, it is well known that transport is almost totally dependent on fossil fuels. Considering that petroleum-based fuels have limited reserves and are blamed for high emission of greenhouse gases, global warming, and climate changes, biodiesel is the best candidate for diesel fuels in diesel engines [25]; moreover, some countries or states have imposed that all diesel fuel must contain part of biodiesel.

Because of rapid industrialization and the implementation of modern economic systems, fuel is one of the highest needs for human well-being; therefore, it is necessary to develop simple, fast, and sensitive methods for its quality control. Metal contaminants are incorporated during the production processes, transport, and storage of ethanol fuel, and it may, even in low concentrations, reduce the performance of fuel and induce the corrosion of some vehicle components, as well as generate environmental pollution [26]. In 2007, a review about $\mathrm{V}$ determination in fossil fuel using atomic spectrometric techniques was published [27], and there were several publications using FAAS in the 1970s. However, none has been published considering direct analysis and FAAS after 2006.

Previous preconcentration steps are commonly necessary to attain the low levels required of the limit of detection (LOD), and flow-based system has been used to improve throughput of analytical procedures by FAAS. Vermicompost commonly used as a garden fertilizer was used as a 
TABLE 1: Selected papers using FAAS in fuel analysis.

\begin{tabular}{|c|c|c|c|}
\hline Sample (s) & Analyte & Remarks & Ref. \\
\hline Biodiesel & $\mathrm{Ca}$ and $\mathrm{Mg}$ & Microemulsion as sample preparation & [35] \\
\hline Ethanol & $\mathrm{Cu}, \mathrm{Fe}, \mathrm{Ni}$, and $\mathrm{Zn}$ & $\begin{array}{l}\text { Cellulose chemically modified with p-aminobenzoic groups was used for } \\
\text { preconcentration step }\end{array}$ & [36] \\
\hline Lubricating oil & $\mathrm{Cu}, \mathrm{Fe}, \mathrm{Ni}, \mathrm{Pb}$, and $\mathrm{Zn}$ & Sulphanilic acid was used to ash samples at $550^{\circ} \mathrm{C}$ & [37] \\
\hline Lubricating oil & $\mathrm{Cu}, \mathrm{Fe}, \mathrm{Ni}, \mathrm{Pb}$, and $\mathrm{Zn}$ & $\begin{array}{l}\text { ANOVA was used to show a trend of concentration increasing of metals in wear } \\
\text { lubricating oils (samples were ashed) }\end{array}$ & [38] \\
\hline
\end{tabular}

biosorbent for preconcentration step for online Cd determination in ethanol fuel in $\mu \mathrm{g} / \mathrm{L}$ range [28]. Moringa oleifera seeds were similarly used for Cd determination in ethanol fuel and flow and chemical parameters were optimized through multivariate designs. Limit of detection under optimized condition was $5.5 \mu \mathrm{g} / \mathrm{L}$ [29]. Cloud Point Extraction (CPE) also has been used for metal ions studies with further determination by FAAS. It was applied to determine $\mathrm{Mn}$ in saline effluents of a petroleum refinery [30].

Direct analysis of fuel samples for metal determination using FAAS presents some general problems, such as volatility, flammability, and immiscibility with water. Moreover, it produces flames that are very rich in fuel and unstable. Reduction of acetylene supply or increase of the flow rate of air is recommended to solve this problem [23]. Direct analysis of ethanol fuel by FAAS based on the use of calibrating solutions prepared in ethanol $95 \% \mathrm{v} / \mathrm{v}$ solvent, such as the analytical procedure proposed by Brazilian Normalizing Committee, does not consider ethanol content variations in samples making it difficult to obtain accurate results in certain cases. Thus, Silva et al. [31] proposed a flow-batch automated procedure for $\mathrm{Fe}$ determination using internal standard by sequential measurements. Nickel was selected as internal standard, and the procedure could improve accuracy and overcome instrumental drifts and ethanol content variation in samples.

Microemulsion has been recently reported for metal determinations in fuels instead of using organic solvents, since it allows the use of aqueous and organometallic standard solutions and it is thermodynamically stable. Microemulsion formation was optimized by phase diagram for $\mathrm{K}$ and Na determination by using Triton X-100 as surfactant, $\mathrm{n}$-pentanol, biodiesel, and aqueous standard $(\mathrm{KCl}$ and $\mathrm{NaCl})$ [32]. Lyra et al. [33] proposed a method for determination of $\mathrm{Ca}, \mathrm{Mg}, \mathrm{Na}$, and $\mathrm{K}$ in biodiesel samples by microemulsion preparation in n-propanol medium and without surfactant use; moreover, $\mathrm{CsCl}$ for $\mathrm{Na}$ and $\mathrm{K}$, and $\mathrm{KCl}$ for $\mathrm{Ca}$ and $\mathrm{Mg}$ were used as ionization suppressors.

Metal monitoring in lubricating oil samples is also important since some metals are added as organometallic compounds to improve some characteristics such as viscosity and corrosion inhibition properties. On the other hand, high metal concentration has been related with the friction and corrosion of the mechanical components of engines. Amorim Filho and Gomes Neto [34] studied three sample preparation procedures: microwave-assisted acid decomposition, direct dilution in kerosene, and oil-in-water emulsion for metal determination by HR-CS-FAAS. Considering direct dilution, it was evaluated the kerosene/light mineral oil ratio to prepare standard solutions since sample and light mineral oil present different viscosities and it can cause accuracy errors. Emulsion was prepared by addition of aviation kerosene or n-hexane, Triton X-100, $\mathrm{HNO}_{3} 50 \% \mathrm{v} / \mathrm{v}$, and the volume was made up with deionized water and the resulting mixture was mixed. Calibration solutions were prepared in $1 \% \mathrm{v} / \mathrm{v} \mathrm{HNO}_{3}$, and the authors pointed out that this is one of advantages of emulsion preparation such as the reduction of the organic solvent wastes and minimization of time and analytical costs. However, the stability and homogeneity of the emulsions must be guaranteed.

Table 1 contains additional publications [35-38] about metal determinations in fuel samples using FAAS.

2.3. Biological Fluids. For human health purposes, analytical procedures for determination of trace elements in environmental and pharmaceutical samples and biological materials have been developed. Analyses of blood, serum, urine, and, most recently, human hair are used in diagnosing trace element deficiencies or to assess environmental or occupational exposure to toxic elements $[39,40]$. Considering the importance of cited sample analysis in routine laboratories, direct analyses are an interesting alternative due to inherent high analytical throughput.

Hair has been considered a biomonitor because the elements are permanently deposited in hair shaft as it grows and are supplied by blood [41]. Hair samples of workers exposed to welding fumes were analyzed by dynamic ultrasonic extraction of $\mathrm{Cd}$ and $\mathrm{Pb}$ using diluted $\mathrm{HNO}_{3}$. Samples previously washed were placed into glass minicolumns and then immersed into a preheated ultrasound bath. Afterwards, the online extraction circuit was filled with the extraction solution ( $2 \mathrm{~mL}$ of $3 \mathrm{~mol} / \mathrm{L}^{-\mathrm{HNO}_{3}}$ ), and the extraction solution was then circulated through the extraction cell under ultrasonic irradiation. After the extraction step, solution extract was homogenized through the mixing coil, the loop of the injection system was then filled with extract solution, and finally, it was injected into an ultrapure water carrier stream that transported it towards the FAAS. Variables of the system were studied by applying a Plackett-Burman design approach. According to the results, hair samples presented $\mathrm{Cd}$ and $\mathrm{Pb}$ concentrations ranged from 0.5 to $4.9 \mu \mathrm{g} / \mathrm{g}$ and from 10.6 to $96.2 \mu \mathrm{g} / \mathrm{g}$ in workers exposed to welding fumes [42]. The same system was also used for $\mathrm{Cu}, \mathrm{Fe}, \mathrm{Mn}$, and $\mathrm{Zn}$ determination in human hair, and $\mathrm{Cu}, \mathrm{Fe}, \mathrm{Mn}$, and 
TABLE 2: Selected papers using FAAS in biological fluids analysis.

\begin{tabular}{|c|c|c|c|}
\hline Sample (s) & Analyte & Remarks & Ref. \\
\hline Urine & $\mathrm{Cr}$ & $\begin{array}{l}\text { Online ultrasound-assisted sample digestion procedure exploiting the stopped-flow } \\
\text { mode, followed by flow injection chromium preconcentration }\end{array}$ & [49] \\
\hline Cosmetics & $\mathrm{Mg}$ and $\mathrm{Zn}$ & Samples were ultrasound-assisted emulsification with a probe system & [50] \\
\hline $\begin{array}{l}\text { Pharmaceutical products } \\
\text { for veterinary use }\end{array}$ & $\mathrm{Cu}$ & Samples were mineralized in $\mathrm{HCl}: \mathrm{HNO}_{3}(20: 1 \mathrm{v} / \mathrm{v})$ & [51] \\
\hline $\begin{array}{l}\text { Nile tilapia (Oreochromis } \\
\text { niloticus) liver tissue }\end{array}$ & $\begin{array}{l}\mathrm{Ca}, \mathrm{Fe} \text {, and } \\
\mathrm{Zn}\end{array}$ & Samples' protein spots were analyzed after mineralization in microwave oven & {$[52]$} \\
\hline Aqueous waste & $\mathrm{Ag}$ & $\begin{array}{l}\text { Evaluation of sorption potential of Moringa oleifera seeds for the decontamination } \\
\text { of } \mathrm{Ag}(\mathrm{I}) \text { in aqueous solutions }\end{array}$ & {$[53]$} \\
\hline
\end{tabular}

Zn concentrations increased considering welder's years of profession [43]. A method based on hair sample slurries was proposed by Ferreira et al. [44] for sequential $\mathrm{Cu}$ and $\mathrm{Zn}$ determination. The hair sample slurries were prepared by cryogenic grinding followed by sonication. The analytical blank was prepared using rice flour. It should be pointed out that external calibration was effective for reaching proper accuracy [44].

The determination of trace elements in biological fluids plays an important role since it is possible to infer about the nutritional status of individuals and assessing their exposure to toxic elements [39]. Thus, Lopes et al. [45] proposed an automatic flow system to sequential determination of $\mathrm{Cu}$ in serum and urine by FAAS. The developed system could adjust the viscosity of serum samples, perform $\mathrm{Cu}$ determination in serum, and preconcentrate $\mathrm{Cu}$ in urine followed by its subsequent elution and determination. The analytical throughput was about 360 determinations/h for $\mathrm{Cu}$ in serum and 12 determinations/h for $\mathrm{Cu}$ in urine. A simple procedure for Pt determination by CS-FAAS was evaluated since Ptbased drugs are commonly used in cancer treatment [46]. A simple $1+1 \mathrm{v} / \mathrm{v}$ dilution of the urine samples with $2 \% \mathrm{v} / \mathrm{v} \mathrm{HCl}$ solution was performed, and flame conditions were optimized by a multivariate $\mathrm{D}$-optimal design. Limit of detection was $0.06 \mathrm{mg} / \mathrm{L}$ in the original sample.

A direct analysis of organic samples is usually difficult due to transport interferences and metal determinations have been done using matrix matching [47]. Copper determination in sugar cane spirits (cachaça) by Fast Sequential FAAS (FS-FAAS) was evaluated by using of internal standardization to reduce transport effects and variation of alcohol content in different samples. Silver, Bi, Co, and $\mathrm{Ni}$ were evaluated as internal standard, and Ag had the best performance for this application. Moreover, the use of internal standard approach improved precision and accuracy of the procedure [48].

Additional studies [49-53] which describe direct analyses of biological samples are presented in Table 2.

2.4. Environmental and Technological Materials. The high popularity achieved by FAAS as a result of its simple operation and lower costs of acquisition and maintenance has qualified it as the method of choice for metal determination in several samples. In this sense, Cuñat et al. [54] checked the accuracy of a man-portable Laser-Induced Breakdown Spectroscopy analyzer (LIBS) used for in situ determination of $\mathrm{Pb}$ in road sediments. The results found for both techniques agreed well being the relative error around 14\% for $\mathrm{Pb}$ concentrations ranging from 480 to $660 \mu \mathrm{g} / \mathrm{g}$. Flame AAS is also commonly applied to quality control of raw material used in industrial applications. For this purpose, Ramos et al. [55] performed XRF (X-ray Fluorescence) and FAAS analysis for $\mathrm{Zn}, \mathrm{Pb}$, and $\mathrm{S}$ determinations in $\mathrm{ZnO}$ samples used to obtain industrial ceramic enamels. A simple strategy adopted to handle samples with high $\mathrm{Pb}$ and $\mathrm{Zn}$ concentrations in FAAS determinations was to reduce the optical pathway by turning the burner to $52^{\circ}$ or $90^{\circ}$, avoiding sample dilution. After comparison between FAAS and XRF results, it was concluded that FAAS exhibited better performance in terms of accuracy and precision. Antimony is regarded as an emerging contaminant due to its use as catalyst in the PET production. The migration of this toxic element to foods and beverages could be a potential source of human intake. Lopez-Molinero et al. [56] developed a novel method for $\mathrm{Sb}$ determination in PET bottles by volatile bromine generation coupled to FAAS. After using several multivariate statistical approaches to reach optimized conditions, the method was applied and the results were compatible with ICP OES (Inductively Coupled Plasma Optical Emission Spectrometry) standard method. Linear range from 1.0 to $17.2 \mu \mathrm{g}$ of $\mathrm{Sb}(\mathrm{V})$ and reproducibility of 4.5 (\% RSD) were obtained as figures of merit. Cespón-Romero and Yebra-Biurrun [57] exploited the good sensitivity of FAAS for $\mathrm{Zn}$ detection and the possibility of coupling it to FIA (Flow Injection Analysis), reducing the sample and reagents consumption, increasing the analytical throughput and minimizing sample manipulation. The method was applied to air quality assessment of workplaces detecting trace amounts of $\mathrm{Zn}$ in welding fumes. Good analytical figures of merit were obtained as LOD of $1.1 \mu \mathrm{g} / \mathrm{m}^{3}$, linear range from 3.7 to $222.2 \mu \mathrm{g} / \mathrm{m}^{3}$ for $15 \mathrm{~min}$ of sampling time, and an analytical throughput of 11 samples/h as well as good repeatability ( $1.6 \%$ of RSD).

Sometimes, the concentrations of the target elements are in very low levels to be directly determined by FAAS. In this sense, CPE was successfully performed for $\mathrm{Cu}$ determination in various matrices [58]. Several variables were 
studied to attain optimized conditions such as $\mathrm{pH}$, complexing agent (4-hydroxy-2-mercapto-6-propylpyrimidine), and surfactant (Triton X-114) concentrations, as well as the temperature. Simplicity, rapidity, and low analysis cost are pointed out as good features of the proposed method. Aiming the development of a method for Bi determination at low concentrations, Şahan et al. [59] proposed an online preconcentration system for Bi quantification by FAAS. A minicolumn packed with a resin containing an iminodiacetate group was used in the experiments. A linear range from 0.1 to $1.0 \mu \mathrm{g} / \mathrm{mL}$ was obtained with an LOD of $2.7 \mu \mathrm{g} / \mathrm{L}$, repeatability of $3 \%$ (for $0.4 \mu \mathrm{g} / \mathrm{mL}$ of $\mathrm{Bi}$ ), and enrichment factor of 20. Several advantages of the method were emphasized as low cost, simplicity, rapidity, and tolerance to high concentration of interferences. Coprecipitation is a simple technique based on phase separation also used for metals determination at trace levels prior to instrumental detections. Aydin and Soylak [60] proposed the separation of $\mathrm{Au}(\mathrm{III}), \mathrm{Bi}(\mathrm{III}), \mathrm{Co}$ (II), $\mathrm{Cr}$ (III), $\mathrm{Fe}$ (III), $\mathrm{Mn}$ (II), $\mathrm{Ni}(\mathrm{II})$, $\mathrm{Pb}(\mathrm{II}), \mathrm{Th}(\mathrm{IV})$, and $\mathrm{U}(\mathrm{VI})$ by using addition of $\mathrm{Cu}(\mathrm{II})-9-$ phenyl-3-fluorone precipitate. The LODs ranged from 0.05 to $12.9 \mu \mathrm{g} / \mathrm{L}$, and the proposed procedure was applied to lake sediments analyses.

Flame AAS as any instrumental method is not free from interferences, such as those derived from sample physicochemical characteristics affecting its transport to the atomizer as well as molecular or atomic absorption that can overlap with the analytical line of the target element [61]. The Cd most sensitive line in FAAS $(228.802 \mathrm{~nm})$ suffers strong overlap with an As absorption line $(228.812 \mathrm{~nm})$. To circumvent this drawback, Waterlot and Douay [61] investigated extracts of soils contaminated with As and $\mathrm{Cd}$ and studied the correction of this interference using a continuum source corrector $\left(\mathrm{D}_{2}\right.$ lamp $)$ and High-Speed SelfReversal Method. The latter was considered the best one to overcome this interference.

In spite of that FAAS has been long recognized as a consolidated monoelement technique, a successful attempt was made to convert this technique in a high speed multielement one. That concept was reached by the proposition of the High-Resolution Continuum Source FAAS (HR-CS FAAS). Nevertheless, the typical narrow linear calibration ranges commonly addressed to FAAS are still observed in HR-CS FAAS. Thus, Raposo Júnior et al. [62] evaluated the use of secondary line and the side pixel registration strategies in HR-CS FAAS to extend its linear calibration range for the multielement determination of $\mathrm{Cu}, \mathrm{Fe}, \mathrm{Mn}$, and $\mathrm{Zn}$ in DTPA soil extracts.

Noroozifar et al. [63] demonstrated the versatility of FAAS for the indirect determination of cyanide ions in an FIA-FAAS system. In this study, the authors tested four solid-phase reagents of $\mathrm{Ag}_{2} \mathrm{X}\left(\mathrm{X}=\mathrm{SO}_{3}{ }^{2-}, \mathrm{Cr}_{2} \mathrm{O}_{7}{ }^{2-}, \mathrm{C}_{2} \mathrm{O}_{4}{ }^{2-}\right.$, and $\mathrm{CO}_{3}{ }^{2-}$ ) and several parameters were optimized such as carrier flow rate, $\mathrm{pH}$, loop volume, and the reactor temperature. The final optimized method exhibited good accuracy (near 100\%) and precision (better than 1.2\%), and it was applied for cyanide determination in well and drinking waters and electroplating wastewaters. In a novel approach for inorganic $\mathrm{N}$ speciation with an online FIA-FAAS system,
Noroozifar et al. [64] used Mn(IV) dioxide as an oxidant agent for conversion of nitrite to nitrate ions. In this reaction, the $\mathrm{Mn}(\mathrm{IV})$ ions in the solid phase are converted to $\mathrm{Mn}(\mathrm{II})$ ions which are measured by FAAS. Thus, the Mn absorbance is proportional to the nitrite content in the sample. Nitrate is reduced by a copperized Cd column being analyzed as nitrite. After optimization of parameters such as carrier acid concentration, reactor temperature, loop length and $\mathrm{MnO}_{2}$ concentration, and interference studies, the method was applied to nitrite and nitrate determinations in waters and meat samples.

It is well recognized that total metal contents are poor indicators of the real menace the toxic metallic species can play in the environment. So, speciation and fractionation procedures have been proposed to assess different pools of metals and infer about bioavailability and bioaccessibility. In this sense, Frankowski et al. [65] presented a method for $\mathrm{Al}$ speciation in soil samples using an HPLC-FAAS (High Performance Liquid Chromatography-FAAS) hyphenated technique. The major $\mathrm{Al}$ species found in this study were related to 2 chromatographic peaks: the first eluted (related to $\mathrm{AlF}_{2}{ }^{+}$and $\mathrm{AlF}_{4}{ }^{-}$species) and the second (related to $\mathrm{AlF}^{2+}$ and $\mathrm{AlF}_{3}$ species). Pehlivan and Kara [66] proposed an SPE method for Fe speciation in water and sediment samples. Matos and Nóbrega [67] evaluated a method for $\mathrm{Cr}$ speciation in cement and cement-related materials. This determination is important because of the wide use of cement in constructions and the potential dispersion of fine powders of this material in the environment at high distances from the source. It is worth to mention the hazardous effects of hexavalent chromium to the human health. In this work, FAAS was applied to access the total concentration of $\mathrm{Cr}$ after a fusion step. Chromium hexavalent concentration was determined by diphenylcarbazide method after alkaline extraction. In another study of $\mathrm{Cr}$ speciation, $\mathrm{Wu}$ et al. [68] used a crosslinked chitosan-bound $\mathrm{FeC}$ nanoparticles as a highly selective solid-phase extractant of $\mathrm{Cr}$ (III) ions in water samples with subsequent determination by FAAS. Later, total $\mathrm{Cr}$ concentration was assessed by quantitative conversion of $\mathrm{Cr}(\mathrm{VI})$ to $\mathrm{Cr}(\mathrm{III})$ by ascorbic acid. Parameters that could affect the method performance were carefully optimized as $\mathrm{pH}$, sample flow rate, and sample volume. Afterwards, column stability and interference studies were also performed. Besides simplicity, and selectivity, the high enrichment factor (100 fold) and good LOD (52.4 ng/L) are attractive characteristics of the method.

Flow injection analysis coupled to FAAS detection is a highly successful association being used in several studies. The lack of sample manipulation, high analysis throughput, simplicity, and low cost can be addressed to this combination. Mukhtar and Limbeck [69] used FIA-FAAS system to determination of water-soluble $\mathrm{Zn}$ in airborne particulate matters samples. When compared to the batchwise traditional system, the developed method exhibited the further above-mentioned characteristics of an FIA-FAAS and higher sensitivity. Dadfarnia et al. also applied FIAFAAS for indirect determination of anions [70]. In the proposed method, cyanide ions were determined in waters and industrial wastewaters with good accuracy and precision. 
The principle of the method is the use of a minicolumn of Salen [N, $\mathrm{N}^{\prime}$-bis(salicylidene) ethylenediamine] on sodium dodecyl sulfate-coated alumina saturated with $\mathrm{Ag}^{+}$ions. The liquid sample is passed through the column, and its cyanide ions eluted the $\mathrm{Ag}^{+}$ions as cyanide $\mathrm{Ag}$ complexes, which are determined by FAAS. The Ag absorbance is proportional to the cyanide content in the sample.

As is mentioned above, FAAS is commonly applied for metal determinations in several environmental matrices. A sequential extraction procedure based on the BCR scheme was applied for metal fractionation in Chilean soils [71] before and after incubation for 60 days with a biosolid material. In this study, FAAS and ICP-MS (Inductively Coupled Plasma Mass Spectrometry) were used, and $\mathrm{Zn}$ was the element with the highest concentration in the biosolid among the studied analytes $(\mathrm{Cu}, \mathrm{Cr}, \mathrm{Ni}, \mathrm{Pb}$, and $\mathrm{Zn})$. Moreover, it was demonstrated that biosolid application enriched the soils with metals, and the largest pool of metals was in the residual fraction. This fraction is regarded as the most resistant to extraction and exhibited the lowest availability to plants uptake. Sediments and soils are labeled as sinks of pollutants in natural ecosystems being used in various environmental monitoring studies. Silva-Filho et al. [72] analyzed leachate pond sediments from the southeastern Brazil in relation to their contents of $\mathrm{Hg}, \mathrm{Zn}, \mathrm{Fe}$, and $\mathrm{Mn}$. Mercury was analyzed by Cold Vapor AAS (CV-AAS) and the remaining elements by FAAS. Higher element concentration in the upper layers of the sediment cores is consistent with the early development of the Brazilian economy notably after the 1990s with an increasing pattern of metals contamination. Additionally, proposition of analytical strategies to speed up and simplify procedures for metals extraction in environmental matrices is of special relevance. In this sense, Remeteiová et al. [73] used ultrasonic-assisted extraction to reduce the analysis time in the fractionation of gravitation dust sediments. Flame AAS was elected as analytical technique to determine $\mathrm{Cu}, \mathrm{Pb}$, and $\mathrm{Zn}$ in the extracts obtained with the conventional and the proposed method. Raposo Júnior et al. [74] evaluated the concentration of metals in 9 lichen species of the South-Mato Grossense Savannah. The dilution factor applied ( $1 \mathrm{~g}$ of sample to final volume of $50 \mathrm{~mL}$ ) and the concentration range of the analyzed samples (Co, 10.08-24.81; Cr, 18.24-44.26; Cu, 3.23-7.57; Fe, 248.411568.01; Mn, 98.50-397.33; Zn, 14.62-34.79 mg/kg) allowed the adequate application of FAAS. Average concentrations of $\mathrm{Cr}, \mathrm{Mn}$, and Co were higher than samples from nonpolluted areas of Kenya, Nepal, and Italy which may indicate a contribution of anthropogenic sources and accumulation by these organisms. Mosetlha et al. [75] evaluated the use of microdialysis sampling for $\mathrm{Cu}$ and $\mathrm{Ni}$ determination in plant materials. Strong linear correlation between the total concentration of these elements and the concentration in the dialyzed were observed, qualifying this technique as a powerful predictor of metal content in plant tissues without the need of mineralization. In this study, FAAS was applied to access the total concentration of metals, and GF AAS determinations were performed for $\mathrm{Cu}$ and $\mathrm{Ni}$ quantification after the microdialysis procedure. In large urban areas, where vehicles are intensively used for transportation, the neighborhoods of roads and streets suffer severe diffuse contamination by heavy metals coming from fossil fuel burning, tire wears, oil residues, and other related sources as biological powdered material by traffic. Faiz et al. [76] determined $\mathrm{Cd}, \mathrm{Cu}, \mathrm{Ni}, \mathrm{Pb}$, and $\mathrm{Zn}$ concentrations by FAAS in road dust from a heavily anthropogenic impacted highway in Islamabad, Pakistan. These authors calculated some indexes to infer about the pollution, and all of them led to the conclusion that the area has low or middle level of pollution.

\section{Flame Furnace and Hydride Generation}

Since the youth of FAAS, three negative aspects of this technique limit its sensitivity. One is the relatively low efficiency of the pneumatic nebulizer, the second is the short residence time of analyte atoms in the measurement zone, and the third one is the dilution of the atom cloud in the flame gases. Although less sensitive, FAAS is so simple, straightforward, and inexpensive in terms of instruments and running costs that researchers have made great efforts during the last years to develop novel sensitive flame atomization systems.

By arranging a flame furnace over the burner head of a FAAS spectrometer, Gáspár and Berndt [77] and Davies and Berndt [78] improved the sensitivity of FAAS by $2-3$ orders of magnitude for 17 volatile/semivolatile elements (Ag, As, $\mathrm{Au}, \mathrm{Bi}, \mathrm{Cd}, \mathrm{Cu}, \mathrm{Hg}, \mathrm{In}, \mathrm{K}, \mathrm{Pb}, \mathrm{Pd}, \mathrm{Rb}, \mathrm{Sb}, \mathrm{Se}, \mathrm{Te}, \mathrm{Tl}$, and $\mathrm{Zn})$. This arrangement, named thermospray flame furnace AAS (TS-FF-AAS), requires a peristaltic pump, an injector, a ceramic capillary, and a $\mathrm{Ni}$ tube. The applications of TSFF-AAS found in the literature focus mainly on biological, environmental, and food samples.

The typical sensitivity reached by FAAS does not allow determinations of $\mathrm{Cd}, \mathrm{Cu}$, and $\mathrm{Pb}$ in beverages because these elements are usually present in these types of samples at $\mu \mathrm{g} / \mathrm{L}$ levels. For this reason, Schiavo et al. [79] developed a procedure aiming the direct determination of $\mathrm{Cd}, \mathrm{Cu}$, and $\mathrm{Pb}$ in wines and grape juices by TS-FF-AAS, and quantification was based on the standard additions method (SAM). Wine samples were measured after simple dilution, and grape juice samples were analyzed without any pretreatment. The LODs obtained for $\mathrm{Cu}, \mathrm{Cd}$, and $\mathrm{Pb}$ were $12.9,1.8$, and $5.3 \mu \mathrm{g} / \mathrm{L}$, respectively.

The concentration of Se in most samples is usually below FAAS limits of quantification. One alternative to overcome this problem was developed by Rosini et al. [80] when the authors evaluated Se behavior in TS-FF-AAS and determined this element in biological samples. The SAM was applied for Se determination in biological materials and the LOD attained was 95 times lower than that typically reached by FAAS.

In TS-FF-AAS the introduction of a greater sample volume into the atomizer implies in a higher amount of concomitants being inserted together with the analyte and, as a result, elevated background signals are obtained. For this reason, Miranda et al. [81] used background signals and multivariate calibration as a procedure to assess the total concentration of concomitants in TS-FF-AAS. Background signals of 29 solutions containing $\mathrm{Cd}(25 \mu \mathrm{g} / \mathrm{L}), \mathrm{Pb}(500 \mu \mathrm{g} / \mathrm{L})$, and four concomitants $(\mathrm{Ca}, \mathrm{K}, \mathrm{Mg}$, and $\mathrm{Na}$ ) were recorded at $228.8 \mathrm{~nm}$ 
for $\mathrm{Cd}$ and $283.3 \mathrm{~nm}$ for $\mathrm{Pb}$. A pharmaceutical sample containing a total of $3 \mathrm{~g} / \mathrm{L}$ of $\mathrm{Ca}, \mathrm{K}, \mathrm{Mg}$, and $\mathrm{Na}$ was analyzed, and $3 \%$ was the relative error.

In order to bring information about variations in surfaces, shapes, and compositions of tube atomizers, Petrucelli et al. [82] compared the performance of metal tube atomizers composed of $\mathrm{Cr}, \mathrm{Fe}, \mathrm{Mo}, \mathrm{Ni}, \mathrm{Ti}$, and $\mathrm{W}$ and ceramic tubes before and after being used for determinations of $\mathrm{Cd}, \mathrm{Cu}$, $\mathrm{Mn}, \mathrm{Pb}$, and $\mathrm{Zn}$ by TS-FF-AAS in aqueous solutions, food and environmental samples. Nickel tube atomizers presented good performances for $\mathrm{Cd}, \mathrm{Cu}, \mathrm{Pb}$, and $\mathrm{Zn}$ determinations and their lifetimes seemed to be long. Titanium tubes presented excellent results for $\mathrm{Cu}$ determination, but their lifetime was extremely short, due to the fast formation of a $\mathrm{TiO}_{2}$ layer.

Due to the fact that Ti tubes presented good results for $\mathrm{Cu}$ determination, Pereira-Filho [83] evaluated the combination of $\mathrm{Ni}$ and $\mathrm{Ti}$ tubes to increase the $\mathrm{Ti}$ atomizer lifetime. The new arrangement combining both tubes increased the sensitivity approximately four times compared to single $\mathrm{Ni}$ or $\mathrm{Ti}$ tubes. It was possible to use the $\mathrm{Ni} /$ Ti tube for more than $13 \mathrm{~h}$ (around 500 determinations) without a loss of performance. The LOD obtained using a Ni/Ti tube atomizer was $2 \mu \mathrm{g} / \mathrm{L}$ for $\mathrm{Cu}$. A useful and informative review article by Arruda and Figueiredo [84] describes the recent developments in the application of metallic atomizers to FAAS.

Ultrasonic nebulizers (USNs) became popular with ICP OES and ICP-MS. In order to extend the benefits of USN from ICP instruments to flame furnace AAS, Ribeiro et al. [85] proposed the coupling between USN and flame furnace. A significant improvement in the detection power was achieved with the USN-flame furnace AAS system which, according to the authors, is mostly due to the longer residence time of the analyte inside the atomizer and to the absence of dilution by the flame gases as it would occur in FAAS. The LODs obtained by USN-flame furnace AAS for $\mathrm{Cd}, \mathrm{Cu}, \mathrm{Pb}$, and $\mathrm{Zn}$ were 36, 4, 39, and 30 times lower than those typically reached by FAAS with pneumatic nebulization.

A sound strategy for online atom trapping was developed by $\mathrm{Wu}$ et al. [86] for preconcentration purposes. The analyte solution was introduced via a pneumatic nebulizer into the flame-heated furnace by a flow of Ar and the middle part of the flame furnace where the carrier gas impacts was cooled by the sample aerosol. A stainless steel plate was put on the top of the flame burner in the middle to lower the temperature of the flame furnace to facilitate the atom trapping process. Cadmium was selected as the analyte element. With $10 \mathrm{~s}$ preconcentration time, a sensitivity enhancement factor of 730 was achieved and the LOD of the proposed method was $15 \mathrm{ng} / \mathrm{L}$.

A novel method of CPE involving two steps was developed by Wu et al. [87] for the determination of trace Ag in complex matrices by TS-FF-AAS. Firstly, $\mathrm{Cu}$ ion reacts with diethyldithiocarbamate (DDTC) to form $\mathrm{Cu}$-DDTC before it is extracted; secondly, after removing the aqueous phase, a sample or standard solution containing Ag ion is added and another CPE procedure is carried out. Potential interference from coexisting transition metal ions with lower DDTC complex stability was largely eliminated. The LOD obtained was $0.2 \mu \mathrm{g} / \mathrm{L}$ with a sample volume of $10 \mathrm{~mL}$.

A sensitive method for the determination of trace $\mathrm{Cd}$ in rice and water by using flow injection online precipitationdissolution in a knotted reactor (KR) as a preconcentration procedure for TS-FF-AAS was developed by Wen et al. [88]. Sample solution and the precipitating reagent were mixed online in a KR. Then, the resultant precipitate of Cd hydroxide was eluted with $1 \mathrm{~mol} / \mathrm{L} \mathrm{HNO}_{3}$ and the eluant analysed by TS-FF-AAS. The LOD was $0.04 \mu \mathrm{g} / \mathrm{L}$ with a sensitivity enrichment factor of 34 using a sample volume of $4 \mathrm{~mL}$.

Using a fast sequential FAAS and a Ni flame furnace, Pereira-Filho [89] performed the sequential determination of $\mathrm{Cd}, \mathrm{Cu}, \mathrm{Pb}$, and $\mathrm{Zn}$. A significant improvement in the analytical throughput of TS-FF-AAS was obtained. Limits of detection obtained for $\mathrm{Cd}, \mathrm{Cu}, \mathrm{Pb}$, and $\mathrm{Zn}$ were $0.3,7.5$, 4.4, and $0.3 \mu \mathrm{g} / \mathrm{L}$, respectively.

A review article by Bezerra et al. [90] covers the recent developments and applications in the production of thermosprays into flame furnaces to improve the analytical sensitivity in atomic absorption. Principles, characteristics, and instrumentation of TS-FF-AAS are discussed.

Significant improvements in the LODs of FAAS may also be achieved by chemical vapor generation, mostly using hydride generation and in-atomizer trapping for the determination of As, Bi, Cd, Ge, Hg, In, Pb, Sb, Se, Sn, Te, and Tl. Since in situ trapping technique allows a significant enhancement in sensitivity, Matusiewicz and Krawczyk [91] evaluated the analytical performance of a coupled volatile species generation-integrated atom trap atomizer FAAS system for the determination of $\mathrm{Cd}$ and $\mathrm{Pb}$ in reference materials. Vapors of $\mathrm{PbH}_{4}$ and $\mathrm{Cd}^{0}$ were atomized in an air-acetylene flame-heated integrated atom trap. A significant improvement in LOD was achieved $(0.05$ and $0.40 \mathrm{ng} / \mathrm{mL}$ for Cd and $\mathrm{Pb}$, resp.) compared with other existing arrangements (water-cooled single silica tube, double-slotted quartz tube, and "integrated trap"). The research group of Matusiewicz also used this device for the determination of In and $\mathrm{Tl}$ [92], $\mathrm{Te}$ [93], $\mathrm{Sb}$ [94], Bi [95], As and Se [96], Ge and Sn [97], Hg [98], As, Bi, Cd, In, Pb, Se, Te and Tl [99], and Ni [100].

An atom trapping approach was used by Ertas et al. [101] to determine $\mathrm{Pb}$ by hydride generation FAAS. Lead hydride, generated online by reacting $\mathrm{Pb}$ in hydrochloric acidpotassium ferricyanide medium with $\mathrm{NaBH}_{4}$, was trapped on the interior walls of a slotted T-tube. Atomization was achieved by aspirating $50 \mathrm{~mL}$ of methyl isobutyl ketone. The LOD obtained was $0.075 \mu \mathrm{g} / \mathrm{L}$ for $7.8 \mathrm{~mL}$ of blank solution. Then, the method was successfully applied to determine $\mathrm{Pb}$ in certified reference materials.

Online atom trapping inside a Ni flame furnace using chemical vapor generation for sample introduction was successfully applied by Wu et al. [102] for the determination of trace $\mathrm{Cd}$ in high-salinity water samples by FAAS. Volatile species were generated upon reaction with potassium borohydride and then trapped into a flame furnace using $\mathrm{N}_{2}$ as the carrier gas. The LOD was $20 \mathrm{ng} / \mathrm{L}$.

Since organic solvents are recognized as interferents in the determination of hydride forming elements, Karadjova et al. [103] investigated the interference effects of various 
organic solvents miscible with water on As determination by hydride generation AAS employing two types of flame atomizers: miniature diffusion flame and flame in flame. The best tolerance to interferences was obtained by using flame in flame atomization together with higher $\mathrm{Ar}$ and $\mathrm{H}_{2}$ supply rates and elevated observation heights.

The traditional monoelement hydride generation AAS with a quartz tube atomizer is mainly applied for single element measurements which greatly increase analysis time and reagent consumption. In order to enhance the analytical throughput, Guerra et al. [104] successfully employed a fast sequential FAAS and hydride generation AAS to sequentially determine $\mathrm{As}$ and $\mathrm{Sb}$ in bottled mineral waters. Adequate sensitivity, high throughput and minimization of reagents, and sample consumption are the attractive features of the developed method. Limits of detection obtained for As and Sb were 0.15 and $0.14 \mu \mathrm{g} / \mathrm{L}$, respectively.

\section{Chemometrics Applications}

Chemometrics combines the use of mathematics and statistics in chemistry, and its application is devoted to extract the maximum of information from a chemical system. The use of optimization strategies for methods development is useful because few experiments are needed and it is possible to identify the interaction among the investigated variables. Santos et al. [105], for instance, applied simplex approach to optimize an automated online preconcentration system for $\mathrm{Mn}$ determination. The authors observed an LOD of $2.0 \mu \mathrm{g} / \mathrm{L}$.

Khajeh et al. [106] used a Doehlert design to optimize a microwave-assisted extraction for $\mathrm{Cu}$ and $\mathrm{Zn}$ determination in cereal samples using FAAS. The best work conditions were observed with $110^{\circ} \mathrm{C}, 176 \mathrm{~W}$, and $16 \mathrm{~min}$. In another study Khajeh and Sanchooli [107] used a Box-Behnken design to optimize microwave-assisted extraction for Fe and $\mathrm{Zn}$ determination in celery. The best conditions achieved were $80^{\circ} \mathrm{C}, 105 \mathrm{~W}$, and $9 \mathrm{~min}$. A microwave-assisted acid digestion method was also investigated by Rojas et al. [108] for metals determination in biomorphic ceramic samples. The authors used a $3^{3}$ full factorial design, and three variables were studied: volumes of $\mathrm{HNO}_{3}$ and $\mathrm{HF}$ and digestion time. Microwave-assisted leaching was studied by Soriano et al. [109] for $\mathrm{Cu}, \mathrm{Fe}, \mathrm{Mn}$, and $\mathrm{Zn}$ determination in multivitamin/multimineral supplements.

Mixture design was used by Bezerra et al. [110] to optimize a method for $\mathrm{Mn}$ and $\mathrm{Zn}$ determination in tea leaves employing slurry sampling. The method was tested in certified reference samples, and the best results were obtained with a mixture composed by $2.0 \mathrm{~mol} / \mathrm{L} \mathrm{HNO}_{3}, 2.0 \mathrm{~mol} / \mathrm{L}$ $\mathrm{HCl}$, and $2.5 \% \mathrm{v} / \mathrm{v}$ Triton $\mathrm{X}-100$ in the proportions of $50 \%$, $12 \%$, and $38 \% \mathrm{v} / \mathrm{v}$, respectively. A combination of sorbent material and flow injection was used by Anthemidis et al. [111] for $\mathrm{Pb}$ determination, and the experimental variables were optimized using factorial design. Santelli et al. [112] optimized a digestion procedure using a focused microwave system for $\mathrm{Fe}, \mathrm{Mn}$, and $\mathrm{Zn}$ determination in food samples. The best conditions were $12 \mathrm{~min}, 260 \mathrm{~W}$, and $42 \% \mathrm{v} / \mathrm{v}$ of $\mathrm{H}_{2} \mathrm{O}_{2}$.
A full factorial design was used by Kenduzler et al. [113] to study the preconcentration variables for $\mathrm{Cr}$ (III) determination. The solid phase was composed by an Amberlite 36 resin. In another strategy, Portugal et al. [114] used $\mathrm{CPE}$ for $\mathrm{Cd}$ and $\mathrm{Pb}$ determination in drinking water. The variables were studied using two-level factorial design and Doehlert design. Dutra et al. [115] developed an online preconcentration system for $\mathrm{Zn}$ determination in biological samples. The authors used a minicolumn filled with silica gel and chemically modified with $\mathrm{Nb}(\mathrm{V})$ oxide $\left(\mathrm{Nb}_{2} \mathrm{O}_{5^{-}}\right.$ $\mathrm{SiO}_{2}$ ). In addition, the variables were investigated with full factorial and Doehlert designs. Ferreira et al. [116] developed a preconcentration procedure for determination of $\mathrm{Cu}$ and $\mathrm{Zn}$ in food samples by sequential multielement FAAS. The optimization step was performed using a Box-Behnken design and three variables investigated: solution $\mathrm{pH}$, reagent concentration, and buffer concentration.

Moreda-Piñeiro et al. [117] investigated systematic errors when using FAAS and ETAAS (Electrothermal AAS) to analyze biological materials. The authors combined experimental design and PCA (Principal Component Analysis) and concluded that the use of slurry sampling technique in ETAAS and FAAS and the determination of high element concentrations by ETAAS have led to poor precision.

There are several publications applying chemometric methods for treatment of data obtained by FAAS itself or FAAS associated with ICP OES and ICP-MS. For instance, Amorim et al. applied PCA and hierarchical cluster analysis (HCA) for classifying green and roasted coffee and demonstrated that the main elements for discrimination were $\mathrm{Ca}$, $\mathrm{Cu}, \mathrm{Fe}, \mathrm{Mg}, \mathrm{K}$, and $\mathrm{Na}$ [118]. Similarly, Madejczyk and Baralkiewicz applied cluster analysis for FAAS and ICP-MS data and showed that the source of honey samples correlated with their chemical composition [119]. Similar approaches were applied for Brazilian coffees cultivated by conventional and organic agriculture [120], for Salvia fruticosa [121] and traditional Chinese medicine formula [122]. All these works demonstrated that analytical information may be expanded when associating reliable results obtained by FAAS or other spectroanalytical methods and chemometry.

\section{Applications Based on Preconcentration Step}

5.1. Speciation. From recent developments in analytical techniques, it is well known that the determination of the total concentration of elements does not provide enough information on important parameters such as mobility, toxicity, bioavailability, and essentiality. Thus, a more detailed analysis usually requires a study of chemical speciation, which according to IUPAC is the analytical activity which is able to identify and/or measure the amounts of one or more chemical species present in the sample [123-125].

In the literature, several methods are utilized in elemental determinations, including sample preparation and preconcentration steps prior to detection. Some preconcentration methods such as SPE, CPE, coprecipitation, liquid-liquid extraction, and ion exchange are used for speciation and separation of the different species. Pena-Pereira et al. described 
an overview of three miniaturized methods that have been applied to preconcentrate and extract different inorganic analytes in various matrices. Several drawbacks which make liquid-liquid extraction time consuming and expensive such as large volume of samples and reagents and the consequent generation of large amounts of residues were also discussed. New methods capable of minimizing such drawbacks like single-drop microextraction (SDME), in which only a small fraction of the analyte is preconcentrated, hollow fiber liquid-phase microextraction (HF-LPME), used to extract and preconcentrate analytes from complex samples, and dispersive liquid-liquid microextraction (DLLME), a simple, fast microextraction based on the use of an appropriate extractant, were presented. Relevant applications in trace metal determinations for each of these methods were also presented and discussed [126].

Dispersive LLME combined with FAAS was applied for speciation of $\mathrm{Cr}$ in water. After optimizing important parameters, such as time, type of solvent, salinity, $\mathrm{pH}$, and amount of chelating agent, enrichment factors of 275 and 262 and LODs of 0.07 and $0.08 \mu \mathrm{g} / \mathrm{L}$ for $\mathrm{Cr}(\mathrm{VI})$ and total $\mathrm{Cr}$ were obtained, respectively [127].

The determination of $\mathrm{Cr}$ species is important in analytical chemistry and toxicological studies because the oxidation state significantly affects the metal toxicity. It is well known that $\mathrm{Cr}(\mathrm{III})$ is considered essential while $\mathrm{Cr}(\mathrm{VI})$ is toxic to humans. Tokalioğlu et al. developed a method for indirect speciation of $\mathrm{Cr}$ applying SPE with a new chelating resin (poly $\mathrm{N}$-(4-bromophenyl)-2-methacrylamide-co-2-acrylamido-2-methyl-1-propanesulfonis acid-co-divinylbenzene). Some parameters such as eluent type, effect of $\mathrm{pH}$, sample volume, sample solution flow rate, and effect of interfering ions on $\mathrm{Cr}$ (III) preconcentration were studied. This specie was separated from $\mathrm{Cr}(\mathrm{VI})$ and preconcentrated using a column containing the new resin. The $\mathrm{Cr}(\mathrm{VI})$ concentration was estimated indirectly by subtracting the $\mathrm{Cr}$ (III) values determined. Total $\mathrm{Cr}$ was determined after reducing $\mathrm{Cr}(\mathrm{VI})$ to $\mathrm{Cr}(\mathrm{III})$ [128].

Long et al. proposed a novel and miniaturized microsequential injection bead-injection lab-on-valve ( $\mu$ SI-BI-LOV) for determination of bioavailable $\mathrm{Cr}(\mathrm{VI})$ in soil with detection by ETAAS. The proposed method offers several advantages as immediate separation between concomitant preconcentration and released chromate, minimization of interconversions, and enhanced accuracy. The method accuracy was evaluated using spikes with water-soluble $\mathrm{Cr}(\mathrm{VI})$ salts at different concentration levels and applied for high levels of bioavailable chromate in soils [129].

Speciation of As is necessary due to the different levels of toxicity of its species: inorganic ions are more toxic than organic species. Tian et al. [130] developed a method for As speciation based on interfacing solid phase preconcentration, liquid chromatography with gradient separation, and hydride generation-quartz FAAS (SI-HPLC-GHG-QFAAS). A $\mathrm{MnO}_{2}$ minicolumn was used to preconcentrate As species, and tetramethylammonium hydroxide (TMAH) was used as eluent. Arsenium(III) was converted to $\mathrm{As}(\mathrm{V})$ via oxidation by $\mathrm{MnO}_{2}$ and the As(III)-PDC complex formed by the reaction with ammonium pyrrolidine dithiocarbamate
(APDC) was selectively adsorbed by the cellulose fiber minicolumn. Finally, As(III) was quantified by GFAAS. Enrichment factors of 17, 16.7, 14, 19.2 and LODs of 0.33 , $0.39,0.62,0.019 \mu \mathrm{g} / \mathrm{L}$ were obtained for As (V), MMA, DMA, and As(III), respectively [130]. Table 3 shows more applications [131-134] of preconcentration and speciation.

5.2. Cloud Point Extraction. Despite the intrinsic selectivity of AAS, matrix interference is a critical aspect in trace metal determinations. A wide range of sample preparation methods have been proposed to reduce such effects on the analytical signal by simply destroying the matrix [135], but problems related to soluble, nonvolatile concomitants still remain a challenge for determinations at low concentration levels. In FAAS, the most critical aspects limiting sensitivity are the low sample introduction efficiency, the analyte dilution in the combustion mixture, and the atomic cloud short residence time in the observation zone [136, 137]. Considering these two aspects, that is, matrix interferences and FAAS relatively high LODs, several methods have been proposed to separate the analytes from their original matrix and simultaneously improve FAAS detection power. Electrodeposition [138], preconcentration on polymeric membranes [139], and SPE [140] are some examples of successful procedures used in recent years.

In this context and due to characteristics such as simplicity, low cost, efficiency, use of less toxic reagents, and production of low volumes of residues, CPE has become one of the most popular extraction/preconcentration methods in FAAS determinations [141-150]. Introduced in 1978 by Watanabe and Tanaka [151], CPE is based on the property of some surface-active agents (surfactants or detergents) of being able to aggregate in aqueous solution to form colloidal-sized clusters known as micelles. These surfactants are typically amphiphilic organic substances that present a long hydrophobic chain and either a small charged group or several neutral groups of polar (hydrophilic) nature. The micelle aggregation and phase separation occur when the solution presents a minimum surfactant concentration (so-called, critical micelle concentration, CMC). By carefully changing the solution conditions, for example, temperature, pressure, or ionic strength, the surfactant molecules become large aggregates (surfactant-rich phase) which can dissolve metal complexes and are eventually separated from the bulk aqueous solution (surfactantpoor phase) [152-154]. Probably due to characteristics such as low toxicity, versatility, and typically low cloud point temperatures, nonionic surfactants are by far the most used in CPE methods [141-150]. Among those, the most popular is $\alpha$-[p-(1,1,3,3-tetramethylbutyl)phenyl]- $\omega$ hydroxylpolyoxyethylene (Triton X-114), with a cloud point temperature in the $23-25^{\circ} \mathrm{C}$ range and a $\mathrm{CMC}$ of $0.17-$ $0.30 \mathrm{mmol} / \mathrm{L}$ [152]. In order to extract metals from aqueous solutions into hydrophobic surfactant aggregates, a complexing agent is usually required. A wide range of reagents is available and APDC is one of the most commonly used [155157]. On the other hand, the possibility of using just the surfactant in a CPE-FAAS procedure has been demonstrated by Candir et al. [158]. In this work, polyethylene glycol 


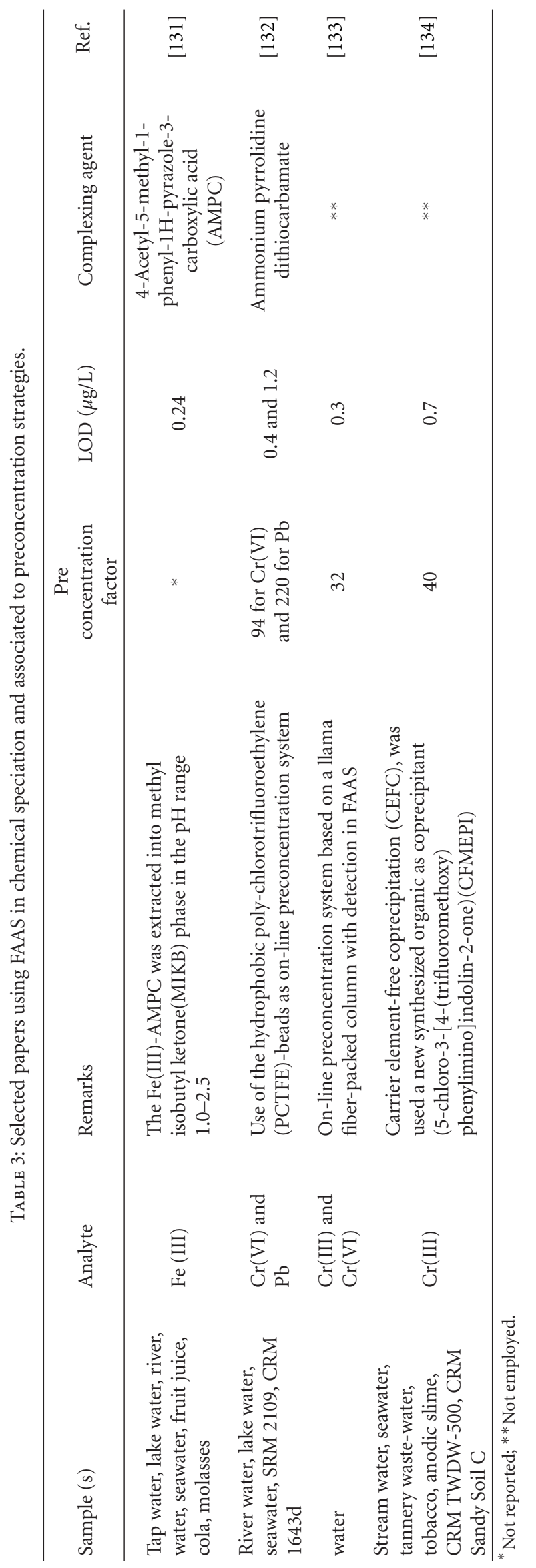


sorbitan monooleate (Tween 80 ) was used simultaneously as complexing agent and surfactant to determine $\mathrm{Bi}, \mathrm{Cd}, \mathrm{Cr}, \mathrm{Cu}$, $\mathrm{Ni}$, and $\mathrm{Pb}$ in water, sediment, and food samples.

Cloud point extraction has been used to improve FAAS capabilities for the determination of several elements. Enrichment factors (i.e., the ratio between calibration curve slopes with and without CPE) up to 200 have contributed to lower LODs and allowed applications in difficult matrices such as food, clinical, and environmental samples [146, 147, $158,159]$. For further improvement of sensitivity, CPE has been used in flame furnace methods such as TS-FF-AAS and double-slotted quartz tube atom trap-FAAS (STAT-FAAS). In this case, LODs comparable with more sensitive methods such as GF AAS and ICP-MS and as low as 2.1, 0.082 and $0.04 \mu \mathrm{g} / \mathrm{L}$ for $\mathrm{Co}, \mathrm{Cr}$, and $\mathrm{Cd}$, for example, were obtained in simple procedures using APDC and Triton X-114 [155-157]. Another strategy is to apply flow injection procedures in CPE-FAAS methods to improve sample throughput. Online reactions and entrapment of metal complexes in columns packed with cotton or other synthetic material have been used to determine $\mathrm{Cd}, \mathrm{Co}, \mathrm{Cu}, \mathrm{Mn}, \mathrm{Ni}, \mathrm{Pb}$, and $\mathrm{Zn}$ in food, water, and plant samples, with LODs in the $\mu \mathrm{g} / \mathrm{L}$ range $[146,159,160]$.

Although still restricted to few elements, the sensitivity improvements provided by CPE has allowed FAAS applications in more complex analytical problems, for example, chemical speciation. Chromium and Sn species were determined in water, juice, metal alloys, and soil in procedures using acetylacetone [149], $\alpha$-polyoxymetalate [161], 1-(2pyridilazo)-2-naphtol (PAN) [162], or APDC [157] as complexing agents. An interesting application of CPE in FAAS determinations was described by Silva et al. [144]. A CPE sample pretreatment was used to extract organic compounds containing $\mathrm{P}$ and eventually reduce spectral interferences related to structured background from PO molecules formed in the flame. The surfactant-poor phase from the first CPE procedure was then submitted to a second extraction to separate $\mathrm{Ni}$ as 1,2-thiazolylazo-2naphtol (TAN) complexes. This double CPE method was successfully applied to plant reference samples with a LOD of $5 \mu \mathrm{g} / \mathrm{L}$. Another interesting application took advantage of the different stability constants of metal diethyldithiocarbamate (DDTC) complexes to determine Ag and Cu using Ni-DDTC in a method referred as one-step displacement CPE [163]. Since Ag and $\mathrm{Cu}$ form DDTC complexes with larger stability constants when compared to Ni-DDTC, they can replace $\mathrm{Ni}$ to form Ag- or Cu-DDTC, which are then extracted into the Triton X-114 surfactant-rich phase. This strategy is especially advantageous because it reduces interferences due to DDTC side reactions with concomitant ions during $\mathrm{CPE}$. The only ions capable of replacing $\mathrm{Ni}$ in Ni-DDTC are $\mathrm{Hg}(\mathrm{II}), \mathrm{Pd}(\mathrm{II}), \mathrm{Ag}(\mathrm{I}), \mathrm{Cu}(\mathrm{II})$, and $\mathrm{Tl}(\mathrm{III})$. Thus, the number of interfering concomitant ions is significantly reduced in $\mathrm{Ag}$ and $\mathrm{Cu}$ determinations.

Simplicity, easy implementation, low cost, environment friendliness, robustness, and sensitivity are some characteristics that have made CPE-FAAS an almost perfect combination for trace metal determinations. It has been applied to a myriad of samples in methods with performances comparable to more complex, expensive techniques such as ICP-MS [164].

5.3. Ionic Liquids. Ionic liquids (ILs) are liquids entirely composed by ions and, among their properties, ILs present negligible low vapor pressure under ambient pressures, thermal stability, and high ionic conductivity. The combination of bulky cation and/or anion and conformational flexibility of the ions favor low melt point, at or below $100^{\circ} \mathrm{C}[165$, 166]. Due to physical and chemical characteristics, ILs have been widely used in several analytical applications such as extractions, gas and liquid chromatography, capillary electrophoresis, mass spectrometry, electrochemistry, sensors, and spectroscopy as alternatives to conventional toxic and volatile organic solvents as reported in a review recently published [167].

Cadmium was determined in plastic food packaging materials by online ionic liquid-based preconcentration system by FAAS [168]. Samples were previously digested, and 2-(5-bromo-2-pyridylazo)-5-diethylaminophenol (5Br-PADAP) reagent was used for $\mathrm{Cd}$ complexation. Then, the complex formed in Triton X-100 and pH 9 medium was extracted with ionic liquid 1-butyl-3-methylimidazolium hexafluorophosphate $\left(\left[\mathrm{C}_{4} \mathrm{mim}\right]\left[\mathrm{PF}_{6}\right]\right)$. Rich phase IL was separated in a silica gel microcolumn and eluted with ethanol acidified with diluted $\mathrm{HNO}_{3}$. Differently, Liang and Peng [169] modified silica with ionic liquid $\left(\left[\mathrm{C}_{4} \mathrm{mim}\right]\left[\mathrm{PF}_{6}\right]\right)$ and packed it in a microcolumn for $\mathrm{Cd}$ preconcentration step. Dithizone was used as complexant, and quantitative $\mathrm{Cd}$ adsorption was found in pHs ranging from 9 to 12 . According to the authors, column could be reused for at least 20 adsorption cycles, followed by a regeneration step.

Functionalized ionic liquids (FILs), a new class of ionic liquids, have been studied for metal extraction due to incorporation of different functional groups that can enhance the versatility of ionic liquids and can improve selectivity in some cases. Thiol-functionalized ionic liquid prepared by appending thiol substituted alkyl groups to imidazole and combining with $\mathrm{PF}_{6}{ }^{-}$anion demonstrated high selectivity for $\mathrm{Cd}(\mathrm{II})$ extraction [170].

Bai et al. [171] reported a liquid-phase microextraction procedure for the preconcentration of $\mathrm{Pb}$ in water samples. Dithizone was used as chelating agent and 1-hexyl-3-methylimidazolium hexafluorophosphate $\left[\mathrm{C}_{6} \mathrm{~min}\right]\left[\mathrm{PF}_{6}\right]$ as extraction solvent. Dithizone, $\left[\mathrm{C}_{6} \mathrm{~min}\right]\left[\mathrm{PF}_{6}\right]$ and sample were mixed at $80^{\circ} \mathrm{C}$ and afterwards cooled down for phase separation. Lead complex was enriched in the ionic liquid droplets, and rich phase was dissolved in $150 \mu \mathrm{L}$ methanol and $1.5 \mathrm{~mol} / \mathrm{L} \mathrm{HNO}_{3}$ to $0.8 \mathrm{~mL}$. Mahpishanian and Shemirani [172] developed a procedure based on in situ solvent formation microextraction (ISFME) for the determination of $\mathrm{Cd}$ in water samples and food grade salts by FAAS. Sample solution, $\mathrm{O}, \mathrm{O}$-diethyl dithiophosphate, and $[\mathrm{Hmim}]\left[\mathrm{BF}_{4}\right]$ were transferred to a $5 \mathrm{~mL}$ tube and shacked. Sodium $\mathrm{PF}_{6}$ was added, and a turbid solution was immediately formed. Then, the rich phase was separated by centrifugation, and fine droplets of IL were obtained (about $8 \mu \mathrm{L}$ ). Aqueous phase was removed and the IL-phase was dissolved in $50 \mu \mathrm{L}$ of ethanol. 
Table 4 presents additional publications [173-176] for trace element determinations after preconcentration using ionic-liquids.

5.4. Functionalized Materials. Solid-phase preconcentration/separation techniques are based on the partition between a liquid (sample matrix) and a solid phase (sorbent), and they have been performed for trace metal determination using FAAS since they present enrichment of analytes and/or matrix elimination [177]. Solid-phase extraction can be easily associated with FIA [178] and the mechanism involved, such as adsorption, ion exchange, chelation, or ion pair formation, depends on the sorbent and analyte interactions [179]. Advantages related to simplicity, high enrichment factor, fast regeneration of solid phase, low reagent and sample consumption, and high throughput were cited in previous papers $[180,181]$.

Despite the numerous characteristics used to enable efficient extraction, the choice of the solid sorbent is the most critical step [177]. Various SPE sorbents have been employed for the preconcentration and among solid-phase sorbents; a good alternative to achieve versatile systems that can be applied to a wide range of samples is the use of polymeric solid supports functionalized with complexing reagents [182, 183]. A minicolumn packed with a chloromethylated polystyrene functionalized with N,N-bis(naphthylideneimino)diethylenetriamine (NAPdein) was used for the online enrichment of Cd(II) at pH 7.0 in water samples [184]. Authors included among advantages the procedure its low cost, high stability in extreme $\mathrm{pH}$ values, and good figures of merit, such as LOD of $0.25 \mu \mathrm{g} / \mathrm{L}$, analytical throughput of $20 / \mathrm{h}$, and preconcentration factor of 50 .

A large number of online and offline preconcentration procedures have been developed using commercially Amberlite XAD resin series (styrene-divinyl-benzene copolymer) loaded or functionalized with different ligands due to their good physical and chemical properties such as porosity, high surface area, durability, and purity [179, 185-189]. Amberlite $\mathrm{XAD}-2$ resin functionalized with pyrocatechol was used in an online preconcentration system for $\mathrm{Cd}, \mathrm{Co}$, and $\mathrm{Ni}$ followed by their determination with FAAS [190]. Considering $60 \mathrm{~s}$ of preconcentration time, the enrichment factors were 22, 23, and 25 , and LODs were $0.95,1.98$, and $2.30 \mu \mathrm{g} / \mathrm{L}$ for Cd, Co and $\mathrm{Ni}$, respectively. Improvements in LODs and sensitivities were observed when the preconcentration time was increased to $180 \mathrm{~s}$. The reusability of the minicolumn packed with the resin was monitored, and it could be used for at least 300 cycles.

Six chelating matrices prepared by functionalizing Amberlite XAD-2 and XAD-16 and silica gel were studied as a sorbent for enrichment of Pd [191]. Amberlite XAD-2 and XAD-16 were anchored with 2,3-dihydroxypyridine (DHP) (I and II), Amberlite XAD-2 and XAD-16 were anchored with 2-\{[1-(3,4- dihydroxyphenyl)-methylidene $]$ amino $\}$ benzoic acid (DMABA) (III and IV), and silica gel was anchored with 3,4-dihydroxybenzaldehyde (DHB) and iminodiacetic acid (IDA) (V and VI). According to the authors, all chelating matrices I-VI were suitable for enrichment of Pd; however, IV and VI were the most promising. The pre- concentration factors were in the range $20-150$, and optimum conditions for desorption were evaluated for each sorbent considering $\mathrm{HCl}$ concentration and flow rate. Moreover, addition of thiourea $(c a .3 \% \mathrm{~m} / \mathrm{v})$ to $\mathrm{HCl}$ is essential for eluting Pd from the columns packed with chelating matrices, otherwise recovery is not quantitative.

A new trend in SPE for metal determination is ion imprinted polymers (IIP). Ion IPs are nanoporous polymeric materials, and their syntheses are based on polymerization reactions where an ion template complex with an appropriate ligand (a monomer) creates a three-dimensional system. Afterwards, the template is extracted and a selective cavity is formed [192]. The selectivity of a polymeric adsorbent is based on the specificity of the ligand, on the coordination geometry, coordination number of the ions, and also, on their charges and sizes [193]. In 2006, IIPs were reviewed by Rao et al. [194]. Segatelli et al. [195] evaluated Cd II-imprinted poly(ethylene glycol dimethacrylate-covinylimidazole) synthesized by bulk method, in which 1vinylimidazole was used as bifunctional reagent, for online ion-selective extraction/preconcentration of Cd II ions from aqueous solution for following determination by FAAS. The proposed method was applied for Cd determination in urine and water, the enrichment factor was 38.4, and LOD was $0.11 \mu \mathrm{g} / \mathrm{L}$. Copper(II)-imprinted polymer (Cu-IIP) for $\mathrm{Cu}$ preconcentration by SPE online has been proposed by Walas et al. [196]. Copper-IIP was obtained by copolymerization of Salen-Cu(II) complex with styrene and divinylbenzene using suspension polymerization technique. For microcolumn packing particle between 60 and $80 \mu \mathrm{m}$ in diameter was used and the enrichment factor for $30 \mathrm{~s}$ loading time was 16 . According to the authors, the only parameter that strongly influenced sorption and selectivity was the $\mathrm{pH}$ of the loading solution, and the optimum $\mathrm{pH}$ was 7 .

Additional publications [197-202] based on preconcentration and functionalized materials are presented in Table 5.

5.5. Flotation Methods. Despite the broad use of FAAS in several applications, some inherent characteristics of this technique related to low nebulization efficiency have restricted it to quantification at $\mathrm{mg} / \mathrm{L}$ levels. In order to improve its detection power, some researchers have been proposing different strategies for metals preconcentration in various distinct matrices. A method proposed with this concern is the so-called Floating Organic Drop Microextraction (FODME) [203-206]. The idea behind this preconcentration method was developed by Jeannot and Cantwell [207]. These authors proposed a simple and inexpensive approach using a small drop $(8 \mu \mathrm{L})$ of a hydrophobic solvent immersed in an aqueous solution containing the analyte. After the migration of the analyte from the solution into the drop it was subsequently determined by gas chromatography. Recently, FODME has been used for metals determination by FAAS after they have been properly complexed and extracted from the aqueous solution. This technique was successfully applied for ultratrace levels quantification of $\mathrm{Cd}$ [205], $\mathrm{Cu}$ [203], $\mathrm{Pd}$ [204], and Zn [206] in water samples from natural and synthetic sources. Another outstanding preconcentration method is based on ion-imprinted polymers that hold a 


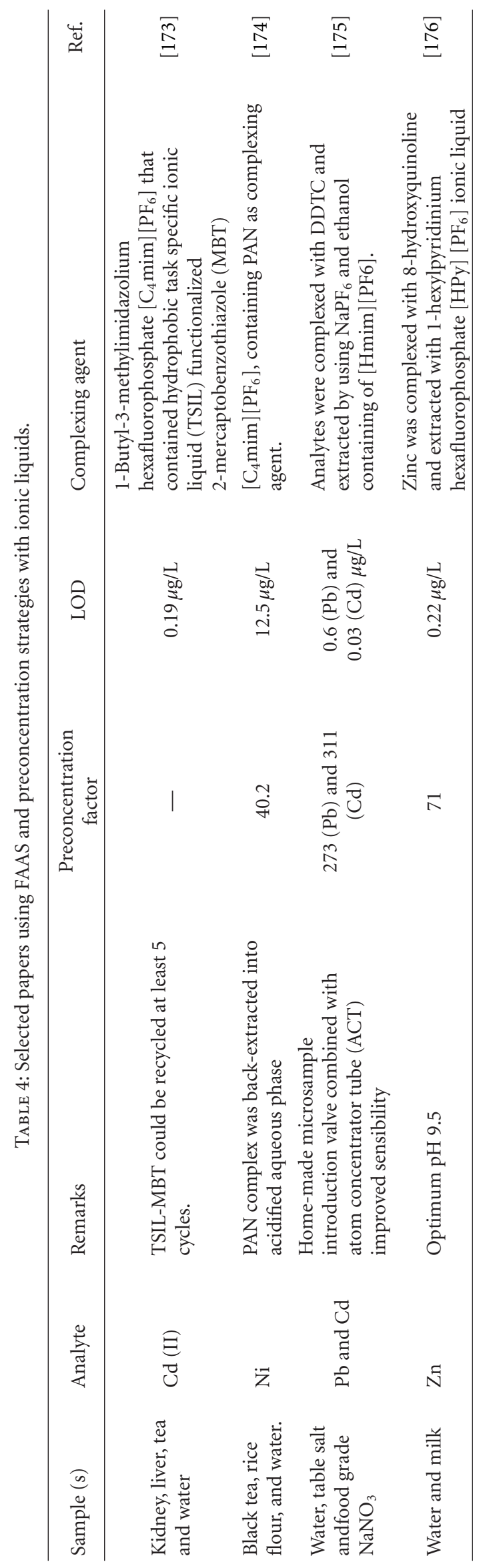




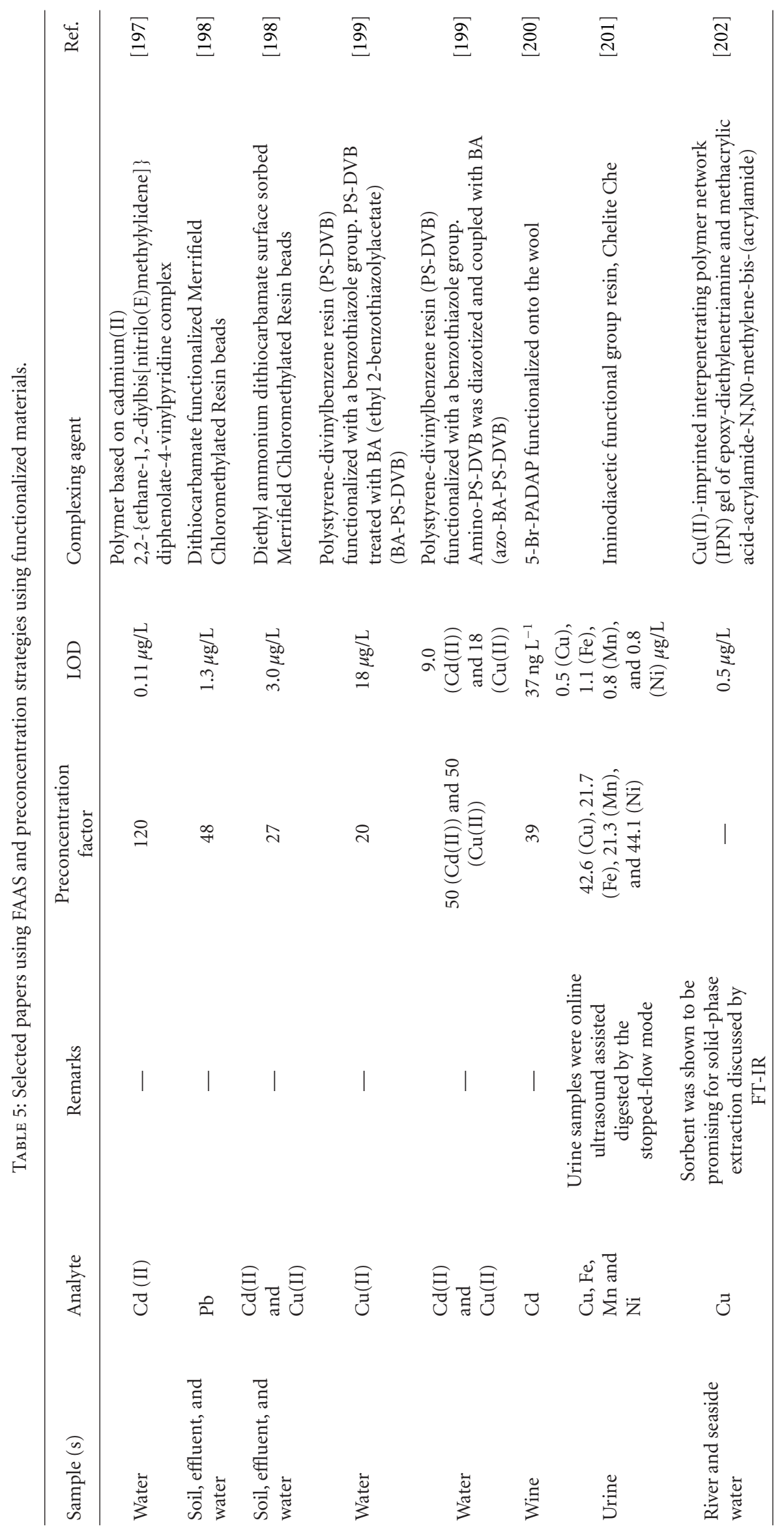


complexing group serving as a solid-phase extractor of ions from liquid solutions. This idea was originally developed by Uezu et al. [208] which proposed a novel molecular imprinting technique named "surface template polymerization." With this new technique, attractive features were attained as rigid polymer matrices, acid resistance as well as high selectivity. Polymers beads formed by $\mathrm{Cu}$ (II) and $\mathrm{Cd}(\mathrm{II})$ have been used for $\mathrm{Cu}$ and $\mathrm{Cd}$ determination, respectively, using FIA-FAAS systems $[196,197,209]$ exhibiting long-term stability and high enrichment factors. Flotation [210] is another commonly used separation-preconcentration method which is based on coprecipitation of the analyte(s) from a high volume solution (usually hundreds of milliliters). The further step is the precipitate flotation to the solution surface promoted by a stream of $\mathrm{N}_{2}$ bubbles from the recipient bottom. Finally, the precipitate is collected and dissolved in a small volume and further determined. This method was applied by Ghaedi et al. [211] for preconcentration of several elements $(\mathrm{Cd}, \mathrm{Co}, \mathrm{Cr}, \mathrm{Cu}, \mathrm{Fe}, \mathrm{Ni}, \mathrm{Pb}$, and $\mathrm{Zn})$ in digestates of plant materials with LODs in the range of 1.3 to $2.4 \mathrm{ng} / \mathrm{mL}$.

5.6. Carbon Nanotubes. As previously stated, FAAS presents, as one of its main limitations, low sensitivity for metals determinations at $\mu \mathrm{g} / \mathrm{L}$ levels and may be strongly affected by matrix effects [212]. Among the various approaches to overcome these drawbacks, it has been proposed preconcentration/separation procedures [213]. The application of natural and synthetic adsorbents is one of the most efficient approaches for this purpose.

The relatively low cost, the efficient removal of metals, and high availability are the major advantages of the application of the adsorbents for preconcentration/separation associated with FAAS.

The use of different types of adsorbents has been given special attention, such as the use of bioadsorbent Geobacillus thermoleovorans subsp. stromboliensis immobilized on Amberlite XAD-4 resin was used in the biosorption of $\mathrm{Cd}(\mathrm{II})$ and $\mathrm{Ni}(\mathrm{II})$ ions in water and food samples [214]. The authors demonstrated that the use of this type of adsorbent is feasible, since they exhibit higher recoveries, economical advantages, simplicity, and environmental safety. Due to the high superficial area and special chemical and physical structures, they are not influenced by toxic substances or extreme parameters (such as low $\mathrm{pH}$ ).

Synthetic adsorbents are also gaining prominence in procedures for preconcentration/separation as the use of 5(p-dimethylaminobenzylidene) rhodanine (PDR) complex on silica gel-polyethylene glycol (Silica-PEG) as a new synthesized adsorbent, for the selective SPE of $\mathrm{Pd}(\mathrm{II})$ in water, dust, and ore samples spiked [215]. The adsorbed complex was eluted using $\mathrm{HCl} /$ acetone mixture, and the concentration of $\mathrm{Pd}(\mathrm{II})$ was determined using FAAS.

We can also use adsorbents chemically modified as presented by Pérez-Quintanilla et al. [216]. This study applied the mesoporous silica chemically modified with 5mercapto-1-methyltetrazole. These authors showed that the matrix effects were reasonably tolerable. In addition, the modified mesoporous silica had high thermal stability and good resistance to hydrolysis and leaching by acids and buffer solutions with repeated use.

Other alternative to combine preconcentration with FAAS is the use of carbon nanotubes, made of carbon atoms which form a hexagonal structure with a thickness of a graphite sheet and cylindrical [217]. The high surface area and the hexagonal arrays of carbon nanotubes provide a strong interaction with other atoms, thus making it a potential adsorbent [218].

The use of multiwalled carbon nanotubes (MWCNTs) as adsorbent for preconcentration of metal ions has been the subject of several studies [219]. Barbosa et al. [178] proposed the application of MWCNTs as a solid sorbent for $\mathrm{Pb}$ preconcentration using a flow system for different types of samples. Moreover, it could be shown that the method is characterized by simplicity, precision, and mainly by absence of chelating agents.

Another interesting study has demonstrated the performance of nanocomposites $\mathrm{Al}_{2} \mathrm{O}_{3}$ /MWCNT as adsorbent for preconcentration of $\mathrm{Ni}(\mathrm{II})$ in water samples [220]. The authors have shown that the minicolumn packed with the nanocomposite did not show the swelling effect and the nanocomposite did not present leakages even when working at high flow rates.

Table 6 presents other preconcentration studies [2, 221255] using biosorbents and carbon nanotubes.

5.7. Other Strategies. The direct elemental determination by FAAS is considered a difficult task when dealing with extremely low concentrations because of insufficient sensitivity, selectivity, or matrix interference. Besides, high levels of concomitant species are often present in the samples to be analysed. To solve these difficulties, a separation step may be required. The separation-preconcentration procedures as $\mathrm{CPE}$, SPE, ion exchange, membrane filtration, solvent extraction, coprecipitation, and liquid-liquid extraction are commonly used prior to detection [256, 257]. Schrijver et al. [258] determined Ag in polymers by solid sampling techniques as laser ablation ICP-MS (LA-ICP-MS), solid sampling electrothermal atomic absorption spectrometry (SS-ETAAS), and wavelength dispersive X-ray fluorescence spectrometry (WD-XRFS), and the accuracy was checked by acid digestion and determination by pneumatic nebulization using ICP-MS or FAAS [258].

The liquid-liquid microextraction system using an automatic sequential injection incorporating a dual-conical microgravitational phase separator was proposed for preconcentration and separation of $\mathrm{Pb}$ in water samples with online determination using FAAS. The APDC was employed as complexing agent and isobutyl methyl ketone (IBMK) used as extraction solvent. The organic phase was collected in the upper cavity of the phase separator. The LOD obtained was $1.4 \mu \mathrm{g} / \mathrm{L}$, and an enhancement factor of 120 was reached for determination of $\mathrm{Pb}$ (II) in water sample [259].

The determination of labile $\mathrm{Al}$ species was made using two methods. The first method applied SPE using chelating resins Iontosorb Oxin and Iontosorb Salicyl, and the second method applied $1 \% \mathrm{~m} / \mathrm{v} 8$-hydroxyquinoline in $2 \% \mathrm{v} / \mathrm{v}$ acetic acid and $0.2 \% \mathrm{~m} / \mathrm{v}$ salicylic acid by a single extraction, and 


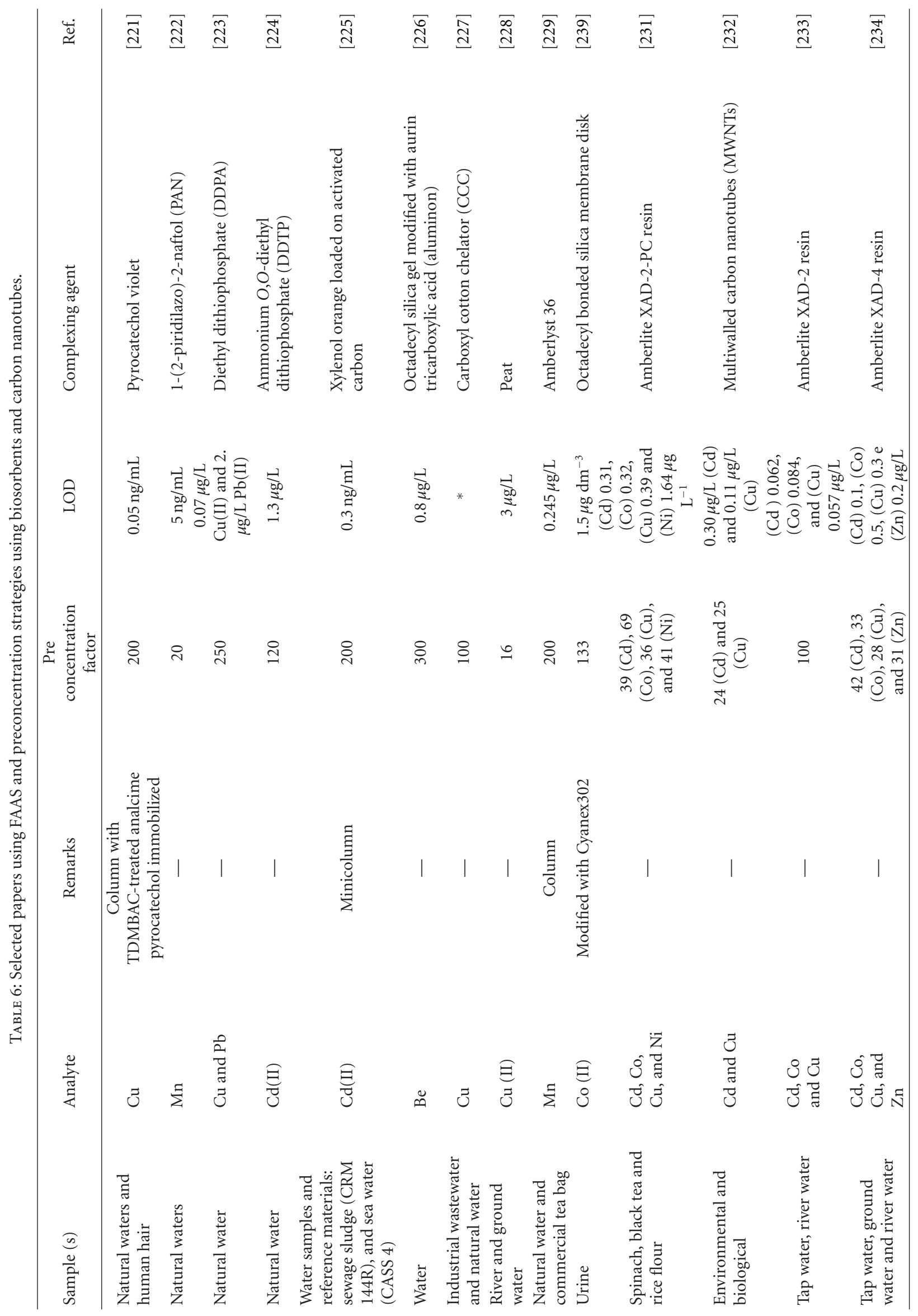




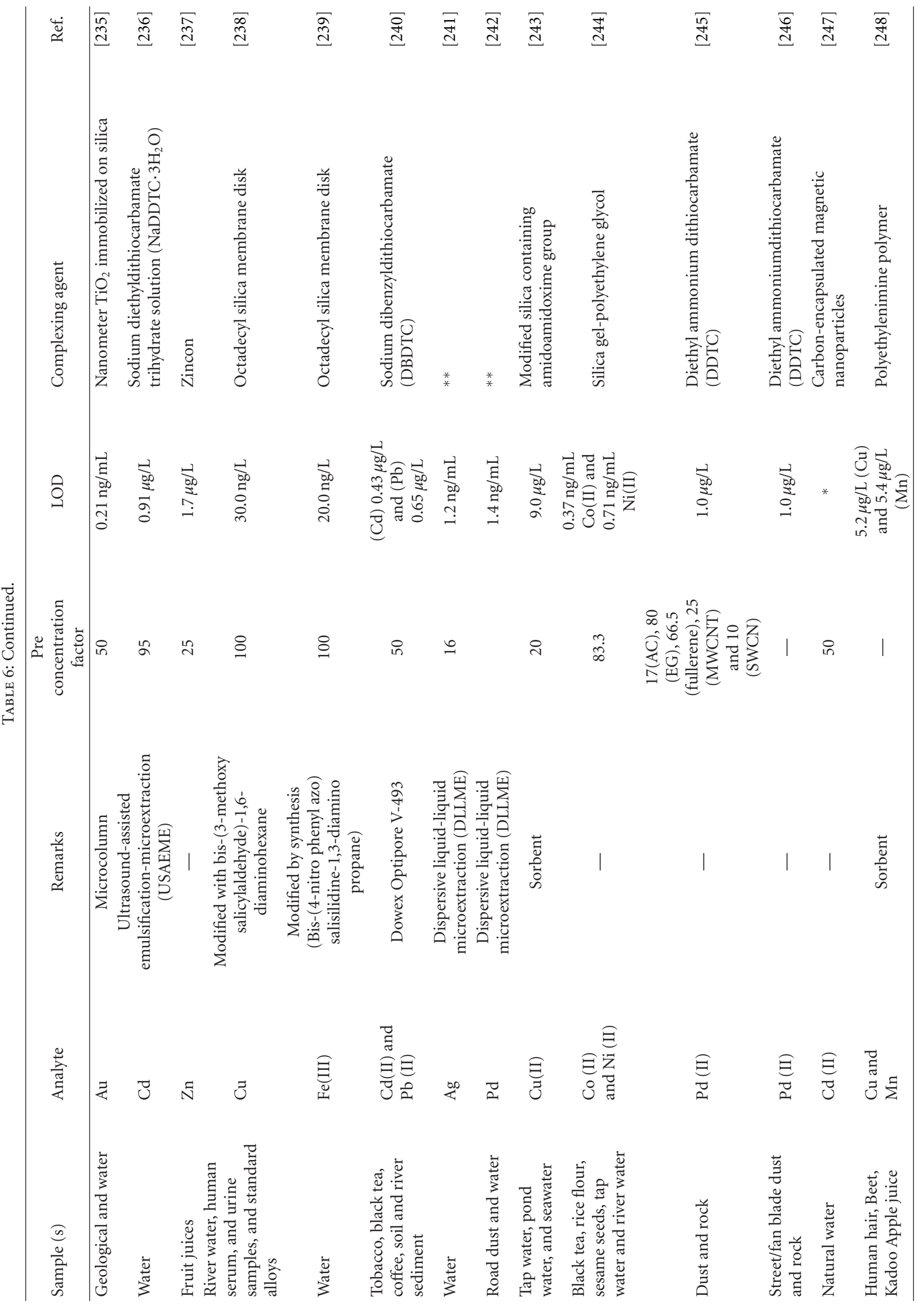




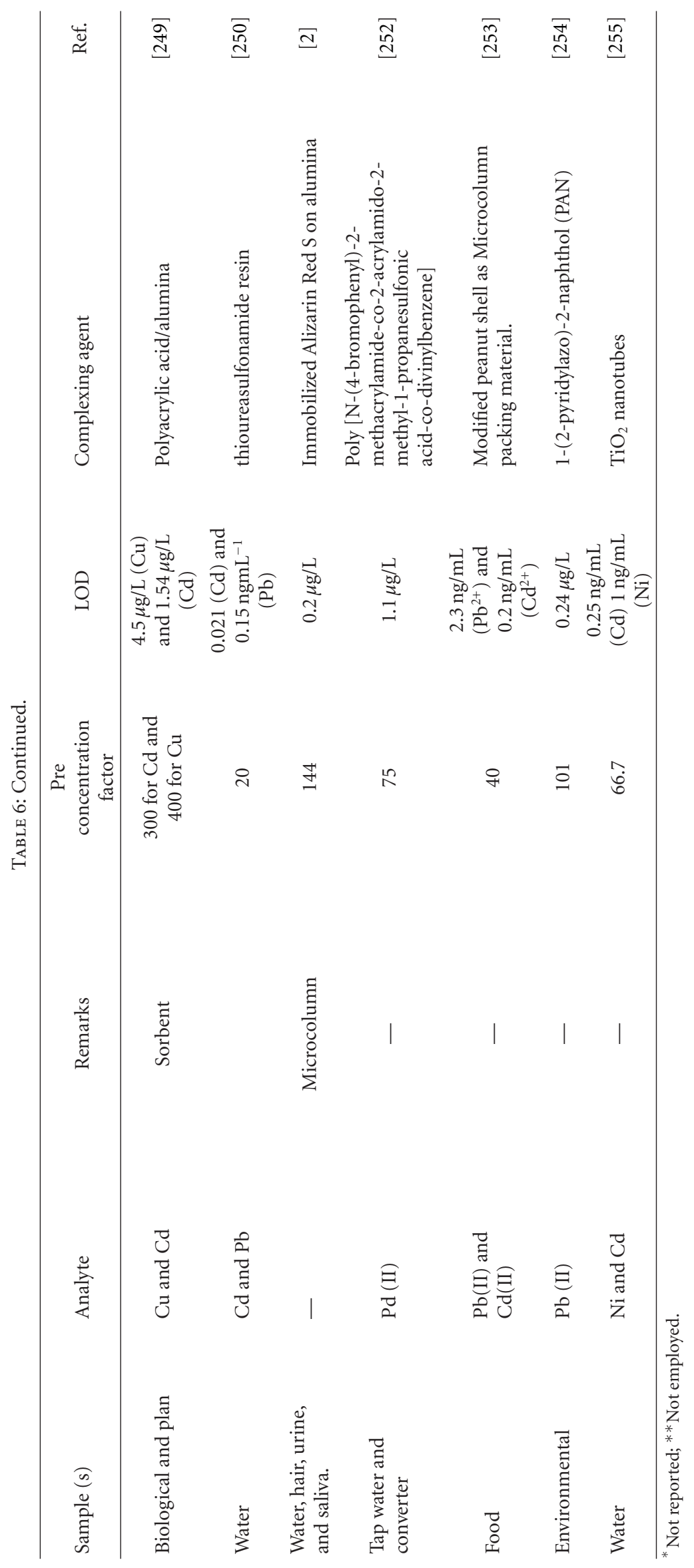




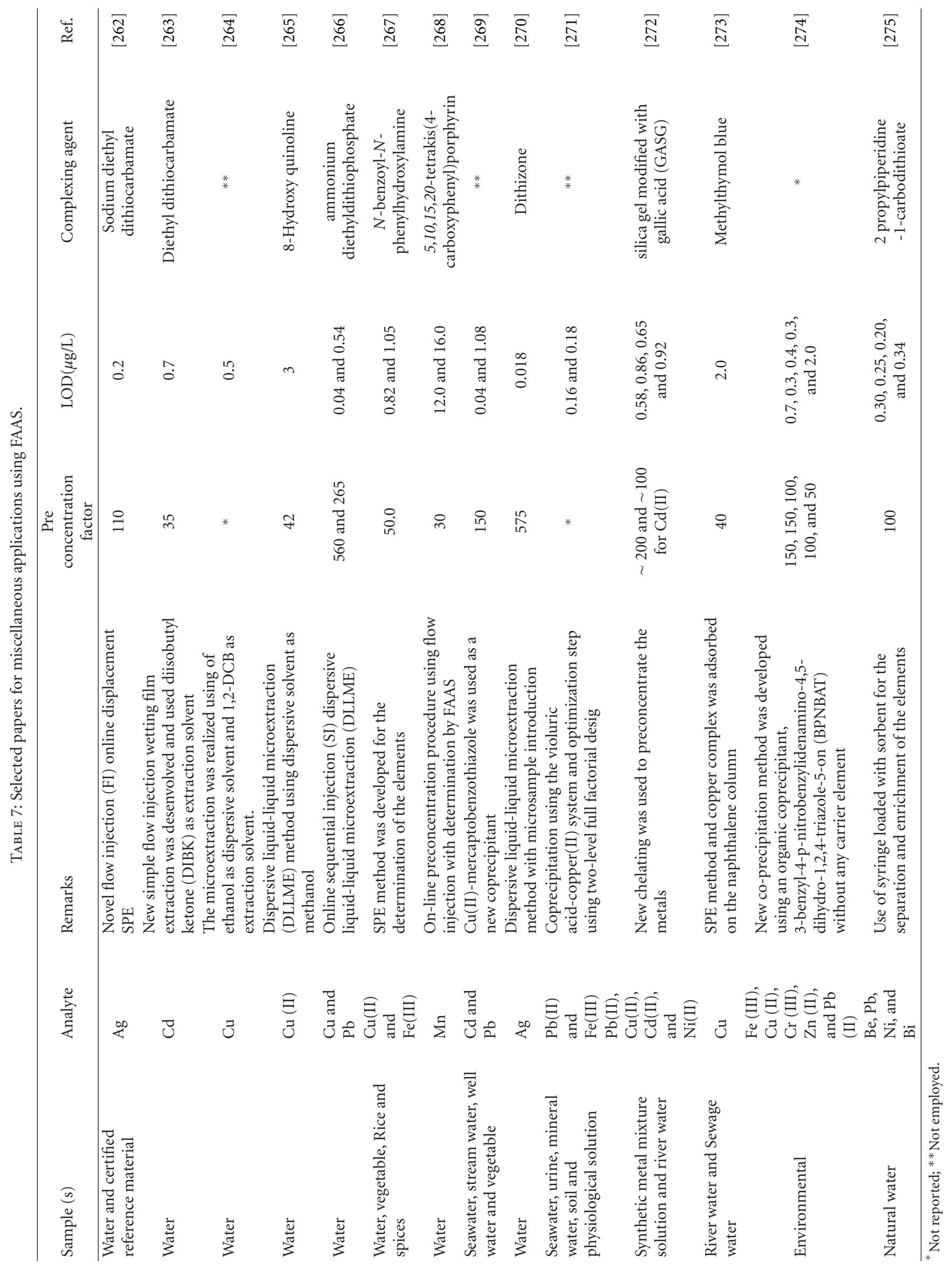


for quantification, FAAS and ICP OES were used. The use of a second method without requiring sample filtration can replace the SPE procedure for determination of $\mathrm{Al}$ in soils [260].

A rapid and straightforward sample treatment employing emulsion by ultrasound system with a probe was developed for determinations of $\mathrm{As}, \mathrm{Cd}, \mathrm{Cr}, \mathrm{Hg}, \mathrm{Mn}, \mathrm{Ni}, \mathrm{Sr}$, and $\mathrm{Zn}$ at trace levels by ETAAS, ICP OES, FAAS, and CV-AAS in cosmetic samples. The emulsion was stable for more than 3 months after applying $1 \mathrm{~min}$ of ultrasonic shaking in a dispersion medium containing $0.5 \% \mathrm{~m} / \mathrm{v}$ of sodium dodecyl sulphate plus $3 \% \mathrm{v} / \mathrm{v}$ of $\mathrm{HNO}_{3}$ or $\mathrm{HCl}$. The accuracy was checked by microwave-assisted digestion and determination by ICP-MS [50].

The SPE procedure was developed for fractionation of $\mathrm{Fe}$ in wine. An adsorbing Amberlite XAD-7HP column followed by a cation exchange Dowex 50W-X8-200 column was used, and three different groups were discriminated, hydrophobic species (phenolic fraction), cationic species and labile forms (cationic fraction), anionic, or neutral species (residual fraction). The results obtained were verified using another adsorbing Amberlite XAD-16 column for Fe determination [261]. More studies [262-275] employing different strategies for preconcentration can be seen in Table 7 .

\section{Conclusions}

Flame atomic absorption spectrometry has several nuances, and its capability to solve analytical challenges is virtually endless. Its applications are observed in various scientific and technological fields with interesting results. In this paper it was possible to see that the FAAS field remains strong and more applications will appear in the coming decades. New advances in commercial instruments and lab-made solutions are enlarging the scope of AAS techniques and surely had brought new horizons for this fertile area in instrumental analysis.

\section{Acknowledgments}

The authors are grateful to Conselho Nacional de Desenvolvimento Científico e Tecnológico (CNPq), Fundação de Amparo à Pesquisa do Estado de São Paulo (FAPESP), and Coordenadoria de Aperfeiçoamento de Pessoal de Nível Superior (CAPES) for grants and fellowships.

\section{References}

[1] F. D. Dias, L. S. Alves, W. N. L. Santos, J. M. David, and S. L. C. Ferreira, "Determination of manganese in cassava leaves by slurry sampling flame atomic absorption spectrometry," Analytical Letters, vol. 42, no. 14, pp. 2206-2213, 2009.

[2] G. C. Brandão, R. M. Jesus, E. G. P. Silva, and S. L. C. Ferreira, "Use of slurry sampling for the direct determination of zinc in yogurt by high resolution-continuum source flame atomic absorption spectrometry," Talanta, vol. 81, no. 4-5, pp. 1357$1359,2010$.

[3] R. A. Bugallo, S. R. Segade, and E. F. Gomez, "Comparison of slurry sampling and microwave-assisted digestion for calcium, magnesium, iron, copper and zinc determination in fish tissue samples by flame atomic absorption spectrometry," Talanta, vol. 72, no. 1, pp. 60-65, 2007.

[4] C. V. S. Ieggli, D. Bohrer, P. C. Nascimento, L. M. Carvalho, and S. C. Garcia, "Determination of sodium, potassium, calcium, magnesium, zinc, and iron in emulsified egg samples by flame atomic absorption spectrometry," Talanta, vol. 80, no. 3, pp. 1282-1286, 2010.

[5] J. B. Pereira, K. G. Fernandes, R. C. S. Muller, and D. C. Palheta, "Direct determination of $\mathrm{Ca}, \mathrm{Mg}, \mathrm{Mn}$ and $\mathrm{Zn}$ in buffalo milk of the Marajó Island by FAAS," Quimica Nova, vol. 32, no. 9, pp. 2333-2335, 2009.

[6] S. P. Han, W. E. Gan, and Q. D. Su, "On-line sample digestion using an electromagnetic heating column for the determination of zinc and manganese in tea leaf by flame atomic absorption spectrometry," Talanta, vol. 72, no. 4, pp. 1481-1486, 2007.

[7] W. N. L. Santos, G. C. Brandão, L. A. Portugal, J. M. David, and S. L. C. Ferreira, "A photo-oxidation procedure using UV radiation $/ \mathrm{H}_{2} \mathrm{O}_{2}$ for decomposition of wine samplesdetermination of iron and manganese content by flame atomic absorption spectrometry," Spectrochimica Acta, vol. 64, no. 6, pp. 601-604, 2009.

[8] P. Pohl and I. Sergiel, "Direct determination of the total concentrations of copper, iron and manganese and their fractionation forms in freshly ripened honeys by means of flame atomic absorption spectrometry," Microchimica Acta, vol. 168, no. 1-2, pp. 9-15, 2010.

[9] P. Pohl, "Manganese and zinc operational fractionation in beer by means of tandem ion exchange column assemblage and flame atomic absorption spectrometry," Microchimica Acta, vol. 159, no. 3-4, pp. 325-332, 2007.

[10] P. Pohl and B. Prusisz, "Fractionation analysis of manganese and zinc in beers by means of two sorbent column system and flame atomic absorption spectrometry," Talanta, vol. 71, no. 4, pp. 1616-1623, 2007.

[11] P. Pohl and B. Prusisz, "Determination of $\mathrm{Ca}, \mathrm{Mg}, \mathrm{Fe}$ and $\mathrm{Zn}$ partitioning in UHT cow milks by two-column ion exchange and flame atomic absorption spectrometry detection," Talanta, vol. 71, no. 2, pp. 715-721, 2007.

[12] P. Pohl and B. Prusisz, "Fractionation of calcium and magnesium in honeys, juices and tea infusions by ion exchange and flame atomic absorption spectrometry," Talanta, vol. 69, no. 5, pp. 1227-1233, 2006.

[13] P. Pohl and B. Prusisz, "Simple and versatile operational fractionation of $\mathrm{Fe}$ and $\mathrm{Zn}$ in dietary products by solid phase extraction on ion exchange resins," Talanta, vol. 71, no. 1, pp. 411-418, 2007.

[14] M. G. A. Korn, E. S. Boa Morte, D. C. M. B. Santos et al., "Sample preparation for the determination of metals in food samples using spectroanalytical methods-a review," Applied Spectroscopy Reviews, vol. 43, no. 2, pp. 67-92, 2008.

[15] J. A. Da-Col, S. M. A. Domene, and E. R. Pereira-Filho, "Fast determination of $\mathrm{Cd}, \mathrm{Fe}, \mathrm{Pb}$, and $\mathrm{Zn}$ in food using AAS," Food Analytical Methods, vol. 2, no. 2, pp. 110-115, 2009.

[16] V. A. Lemos, E. M. Gama, and A. D. Lima, "On-line preconcentration and determination of cadmium, cobalt and nickel in food samples by flame atomic absorption spectrometry using a new functionalized resin," Microchimica Acta, vol. 153, no. 3-4, pp. 179-186, 2006.

[17] V. A. Lemos, D. R. Vieira, C. G. Novaes, M. E. Rocha, M. S. Santos, and R. T. Yamaki, "Preconcentration systems using polyurethane foam/Me-BDBD for determination of copper in food samples," Microchimica Acta, vol. 153, no. 3-4, pp. 193-201, 2006. 
[18] M. C. Yebra and M. H. Bollain, "A simple indirect automatic method to determine total iodine in milk products by flame atomic absorption spectrometry," Talanta, vol. 82, no. 2, pp. 828-833, 2010.

[19] S. L. C. Ferreira, E. G. P. Silva, L. A. Portugal et al., "Evaluation and application of the internal standard technique for the direct determination of copper in fruit juices employing fast sequential flame atomic absorption spectrometry," Analytical Letters, vol. 41, no. 9, pp. 1571-1578, 2008.

[20] S. L. C. Ferreira, A. S. Souza, G. C. Brandão et al., "Direct determination of iron and manganese in wine using the reference element technique and fast sequential multielement flame atomic absorption spectrometry," Talanta, vol. 74, no. 4, pp. 699-702, 2008.

[21] S. R. Oliveira, J. A. Gomes Neto, J. A. Nóbrega, and B. T. Jones, "Determination of macro- and micronutrients in plant leaves by high-resolution continuum source flame atomic absorption spectrometry combining instrumental and sample preparation strategies," Spectrochimica Acta, vol. 65, no. 4, pp. 316-320, 2010.

[22] S. R. Oliveira, J. L. Raposo Jr., and J. A. Gomes Neto, "Fast sequential multi-element determination of $\mathrm{Ca}, \mathrm{Mg}, \mathrm{K}, \mathrm{Cu}$, $\mathrm{Fe}, \mathrm{Mn}$ and $\mathrm{Zn}$ for foliar diagnosis using high-resolution continuum source flame atomic absorption spectrometry: Feasibility of secondary lines, side pixel registration and leastsquares background correction," Spectrochimica Acta, vol. 64, no. 6, pp. 593-596, 2009.

[23] M. G. A. Korn, D. S. S. Santos, B. Welz et al., "Atomic spectrometric methods for the determination of metals and metalloids in automotive fuels-a review," Talanta, vol. 73, no. 1, pp. 1-11, 2007.

[24] L. C. Freitas and S. Kaneko, "Decomposition of $\mathrm{CO}_{2}$ emissions change from energy consumption in Brazil: challenges and policy implications," Energy Policy, vol. 39, no. 3, pp. 1495-1504, 2011.

[25] A. Demirbas, "Importance of biodiesel as transportation fuel," Energy Policy, vol. 35, no. 9, pp. 4661-4670, 2007.

[26] E. L. Silva, D. Budziak, and E. Carasek, "Determination of trace metals in fuel alcohol by FAAS using $\mathrm{Nb}_{2} \mathrm{O}_{5}-\mathrm{SiO}_{2}$ as sorbent material in a flow injection on-line preconcentration system," Analytical Letters, vol. 37, no. 9, pp. 1909-1924, 2004.

[27] F. A. C. Amorim, B. Welz, A. C. S. Costa, F. G. Lepri, M. G. R. Vale, and S. L. C. Ferreira, "Determination of vanadium in petroleum and petroleum products using atomic spectrometric techniques," Talanta, vol. 72, no. 2, pp. 349-359, 2007.

[28] J. N. Bianchin, E. Martendal, R. Mior et al., "Development of a flow system for the determination of cadmium in fuel alcohol using vermicompost as biosorbent and flame atomic absorption spectrometry," Talanta, vol. 78, no. 2, pp. 333336, 2009.

[29] V. N. Alves, R. Mosquetta, N. M. M. Coelho et al., "Determination of cadmium in alcohol fuel using Moringa oleifera seeds as a biosorbent in an on-line system coupled to FAAS," Talanta, vol. 80, no. 3, pp. 1133-1138, 2010.

[30] M. A. Bezerra, A. L. B. Conceição, and S. L. C. Ferreira, "A pre-concentration procedure using cloud point extraction for the determination of manganese in saline effluents of a petroleum refinery by flame atomic absorption spectrometry," Microchimica Acta, vol. 154, no. 1-2, pp. 149-152, 2006.

[31] J. E. Silva, F. A. Da Silva, M. F. Pimentel et al., "A flowbatch internal standard procedure for iron determination in hydrated ethanol fuel by flame atomic absorption spectrometry," Talanta, vol. 70, no. 3, pp. 522-526, 2006.

[32] A. Jesus, M. M. Silva, and M. G. R. Vale, "The use of microemulsion for determination of sodium and potassium in biodiesel by flame atomic absorption spectrometry," Talanta, vol. 74, no. 5, pp. 1378-1384, 2008.

[33] F. H. Lyra, M. T. W. D. Carneiro, G. P. Brandão, H. M. Pessoa, and E. V. De Castro, "Determination of $\mathrm{Na}, \mathrm{K}, \mathrm{Ca}$ and $\mathrm{Mg}$ in biodiesel samples by flame atomic absorption spectrometry (FAAS) using microemulsion as sample preparation," Microchemical Journal, vol. 96, no. 1, pp. 180-185, 2010.

[34] V. R. Amorim Filho and J. A. Gomes Neto, "Different lubricating oil treatments for the determination of $\mathrm{Cu}, \mathrm{Cr}$, $\mathrm{Fe}, \mathrm{Ni}, \mathrm{Sb}, \mathrm{Pb}$, and $\mathrm{Zn}$ by HR-CS FAAS," Analytical Letters, vol. 41, no. 9, pp. 1555-1570, 2008.

[35] A. Jesus, A. V. Zmozinski, J. A. Barbará, M. G. R. Vale, and M. M. Silva, "Determination of calcium and magnesium in biodiesel by flame atomic absorption spectrometry using microemulsions as sample preparation," Energy and Fuels, vol. 24, no. 3, pp. 2109-2112, 2010.

[36] G. R. Castro, J. D. De Oliveira, I. L. Alcântara et al., "Application of cellulose modified with p-aminobenzoic Groups in preconcentration system for determination of $\mathrm{Cu}$, $\mathrm{Fe}, \mathrm{Ni}$, and $\mathrm{Zn}$ in fuel ethanol samples by flame atomic absorption spectrometry," Separation Science and Technology, vol. 42, no. 6, pp. 1325-1340, 2007.

[37] E. L. C. Silveira, L. B. de Caland, C. V. R. De Moura, and E. M. Moura, "Determination of contaminants in used lubricating oils and in wastewater contamined by these lubricants," Quimica Nova, vol. 29, no. 6, pp. 1193-1197, 2006.

[38] E. L. C. Silveira, R. C. Coelho, J. M. Motia Neto, C. V. R. De Moura, and E. M. De Moura, "Determination of metals in lubricating oils, from public transportation, using the faas," Quimica Nova, vol. 33, no. 9, pp. 1863-1867, 2010.

[39] P. J. Parsons and F. Barbosa Jr., "Atomic spectrometry and trends in clinical laboratory medicine," Spectrochimica Acta, vol. 62, no. 9, pp. 992-1003, 2007.

[40] V. A. Lemos and A. L. De Carvalho, "Determination of cadmium and lead in human biological samples by spectrometric techniques: a review," Environmental Monitoring and Assessment, vol. 171, no. 1-4, pp. 255-265, 2010.

[41] K. Chojnacka, A. Zielinska, I. Michalak, and H. Górecki, "The effect of dietary habits on mineral composition of human scalp hair," Environmental Toxicology and Pharmacology, vol. 30, no. 2, pp. 188-194, 2010.

[42] R. M. Cespón-Romero and M. C. Yebra-Biurrun, "Flow injection determination of lead and cadmium in hair samples from workers exposed to welding fumes," Analytica Chimica Acta, vol. 600, no. 1-2, pp. 221-225, 2007.

[43] M. C. Yebra-Biurrun and R. M. Cespón-Romero, "Fast ultrasound-assisted extraction of copper, iron, manganese and zinc from human hair samples prior to flow injection flame atomic absorption spectrometric detection," Analytical and Bioanalytical Chemistry, vol. 388, no. 3, pp. 711-716, 2007.

[44] H. S. Ferreira, W. N. L. Dos Santos, R. P. Fiuza, J. A. Nóbrega, and S. L. C. Ferreira, "Determination of zinc and copper in human hair by slurry sampling employing sequential multielement flame atomic absorption spectrometry," Microchemical Journal, vol. 87, no. 2, pp. 128-131, 2007.

[45] C. M. P. V. Lopes, A. A. Almeida, J. L. M. Santos, and J. L. F. C. Lima, "Automatic flow system for the sequential determination of copper in serum and urine by flame atomic absorption spectrometry," Analytica Chimica Acta, vol. 555, no. 2, pp. 370-376, 2006. 
[46] A. C. Costa Jr., M. A. Vieira, A. S. Luna, and R. C. De Campos, "Determination of platinum originated from antitumoral drugs in human urine by atomic absorption spectrometric methods," Talanta, vol. 82, no. 5, pp. 1647-1653, 2010.

[47] E. A. Hernández-Caraballo, R. M. Avila-Gómez, T. Capote, F. Rivas, and A. G. Pérez, "Classification of Venezuelan spirituous beverages by means of discriminant analysis and artificial neural networks based on their $\mathrm{Zn}, \mathrm{Cu}$ and $\mathrm{Fe}$ concentrations," Talanta, vol. 60, no. 6, pp. 1259-1267, 2003.

[48] K. Miranda, A. G. G. Dionísio, and E. R. Pereira-Filho, "Copper determination in sugar cane spirits by fast sequential flame atomic absorption spectrometry using internal standardization," Microchemical Journal, vol. 96, no. 1, pp. 99-101, 2010.

[49] R. M. Cespón and M. C. Yebra, "Flow injection determination of total chromium in urine of occupationally exposed workers," Microchimica Acta, vol. 164, no. 1-2, pp. 225-229, 2009.

[50] I. Lavilla, N. Cabaleiro, M. Costas, I. De la Calle, and C. Bendicho, "Ultrasound-assisted emulsification of cosmetic samples prior to elemental analysis by different atomic spectrometric techniques," Talanta, vol. 80, no. 1, pp. 109116, 2009.

[51] M. Scripcariu, I. G. Tănase, Ş. Fleschin, V. Magearu, A. A. Bunaciu, and H. Y. Aboul-Enein, "Flame atomic absorption spectrometry assay for copper determination in pharmaceutical products for veterinary use," Analytical Letters, vol. 40, no. 11, pp. 2097-2104, 2007.

[52] P. M. Lima, R. C. F. Neves, F. A. Dos Santos et al., "Analytical approach to the metallomic of Nile tilapia (Oreochromis niloticus) liver tissue by SRXRF and FAAS after 2D-PAGE separation: preliminary results," Talanta, vol. 82, no. 3, pp. 1052-1056, 2010.

[53] C. S. T. Araújo, E. I. Melo, V. N. Alves, and N. M. M. Coelho, "Moringa oleifera Lam. seeds as a natural solid adsorbent for removal of AgI in aqueous solutions," Journal of the Brazilian Chemical Society, vol. 21, no. 9, pp. 1727-1732, 2010.

[54] J. Cuñat, F. J. Fortes, and J. J. Laserna, "Real time and in situ determination of lead in road sediments using a manportable laser-induced breakdown spectroscopy analyzer," Analytica Chimica Acta, vol. 633, no. 1, pp. 38-42, 2009.

[55] S. S. Ramos, D. J. Y. Marco, J. V. G. Adelantado, and A. S. Agulles, "Analytical study of raw materials of zinc oxide used for enamels on industrial ceramics: quantitative analysis of zinc, lead, and sulfur in these samples by X-ray fluorescence and flame atomic absorption spectrometry," Spectroscopy Letters, vol. 39, no. 5, pp. 457-472, 2006.

[56] A. Lopez-Molinero, P. Calatayud, D. Sipiera, R. Falcon, and D. Liñan, "Determination of antimony in poly(ethylene terephthalate) by volatile bromide generation flame atomic absorption spectrometry," Microchimica Acta, vol. 158, no. 34, pp. 247-253, 2007.

[57] R. M. Cespón-Romero and M. C. Yebra-Biurrun, "Determination of trace amounts of zinc in welding fumes by flow-injection flame atomic absorption spectrometry," Spectroscopy Letters, vol. 39, pp. 203-214, 2006.

[58] A. Shokrollahi, M. Ghaedi, S. Gharaghani, M. R. Fathi, and M. Soylak, "Cloud point extraction for the determination of copper in environmental samples by flame atomic absorption spectrometry," Quimica Nova, vol. 31, no. 1, pp. 70-74, 2008.

[59] S. Şahan, S. Saçmaci, U. Şahin, A. Ülgen, and Ş Kartal, "An on-line preconcentration/separation system for the determination of bismuth in environmental samples by FAAS," Talanta, vol. 80, no. 5, pp. 2127-2131, 2010.
[60] F. A. Aydin and M. Soylak, "A novel multi-element coprecipitation technique for separation and enrichment of metal ions in environmental samples," Talanta, vol. 73, no. 1, pp. 134$141,2007$.

[61] C. Waterlot and F. Douay, "The problem of arsenic interference in the analysis of $\mathrm{Cd}$ to evaluate its extractability in soils contaminated by arsenic," Talanta, vol. 80 , no. 2, pp. 716$722,2009$.

[62] J. L. Raposo Jr., S. R. de Oliveira, and N. M. Caldas, "Evaluation of alternate lines of $\mathrm{Fe}$ for sequential multielement determination of $\mathrm{Cu}, \mathrm{Fe}, \mathrm{Mn}$ and $\mathrm{Zn}$ in soil extracts by high-resolution continuum source flame atomic absorption spectrometry," Analytica Chimica Acta, vol. 627, no. 2, pp. 198-202, 2008.

[63] M. Noroozifar, M. Khorasani-Motlagh, and R. Zare-Dorabei, "Application of $\mathrm{Ag}_{2} \mathrm{X}\left(\mathrm{X}=\mathrm{SO}_{3}{ }^{2-}, \mathrm{Cr}_{2} \mathrm{O}_{7}{ }^{2-}, \mathrm{C}_{2} \mathrm{O}_{4}{ }^{2-}\right.$ and $\mathrm{CO}_{3}{ }^{2-}$ ) solid-phase reagents for indirect determination of cyanide in the industrial effluent using FIA-FAAS system," Talanta, vol. 72, no. 5, pp. 1773-1778, 2007.

[64] M. Noroozifar, M. Khorasani-Motlagh, A. Taheri, and M. Homayoonfard, "Application of manganese(IV) dioxide microcolumn for determination and speciation of nitrite and nitrate using a flow injection analysis-flame atomic absorption spectrometry system," Talanta, vol. 71, no. 1, pp. 359-364, 2007.

[65] M. Frankowski, A. Ziola-Frankowska, and J. Siepak, "Speciation of aluminium fluoride complexes and $\mathrm{Al}^{3+}$ in soils from the vicinity of an aluminium smelter plant by hyphenated High Performance Ion Chromatography Flame Atomic Absorption Spectrometry technique," Microchemical Journal, vol. 95, no. 2, pp. 366-372, 2010.

[66] E. Pehlivan and D. Kara, "Iron speciation by solid phase extraction and flame atomic absorption spectrometry using N,N'-bis-(2-hydroxy-5-bromobenzyl)-2-hydroxy-1,3diiminopropane," Microchimica Acta, vol. 158, no. 1-2, pp. 137-144, 2007.

[67] W. O. Matos and J. A. Nóbrega, "Especiação de cromo em cimentos e derivados de cimento brasileiros," Química Nova, vol. 32, no. 8, pp. 2094-2097, 2009.

[68] Y. Wu, Y. Jiang, D. Han, F. Wang, and J. Zhu, "Speciation of chromium in water using crosslinked chitosan-bound $\mathrm{FeC}$ nanoparticles as solid-phase extractant, and determination by flame atomic absorption spectrometry," Microchimica Acta, vol. 159, no. 3-4, pp. 333-339, 2007.

[69] A. Mukhtar and A. Limbeck, "On-line determination of water-soluble zinc in airborne particulate matter using a dynamic extraction procedure coupled to flame atomic absorption spectrometry," Journal of Analytical Atomic Spectrometry, vol. 25, no. 7, pp. 1056-1062, 2010.

[70] S. Dadfarnia, A. M. H. Shabani, F. Tamadon, and M. Rezaei, "Indirect determination of free cyanide in water and industrial waste water by flow injection-atomic absorption spectrometry," Microchimica Acta, vol. 158, no. 1-2, pp. 159163, 2007.

[71] I. Ahumada, A. Maricán, M. Retamal et al., "Assessment of extractability of $\mathrm{Cu}, \mathrm{Cr}, \mathrm{Ni}, \mathrm{Pb}$ and $\mathrm{Zn}$ in some chilean biosolid-amended soils by using BCR sequential extraction procedure," Journal of the Brazilian Chemical Society, vol. 21, no. 4, pp. 721-730, 2010.

[72] E. V. Silva-Filho, S. M. Sella, E. C. Spinola, I. R. Santos, W. Machado, and L. D. Lacerda, "Mercury, zinc, manganese, and iron accumulation in leachate pond sediments from a refuse tip in Southeastern Brazil," Microchemical Journal, vol. 82, no. 2, pp. 196-200, 2006. 
[73] D. Remeteiová, S. Ruzicková, and R. Rusnák, "Ultrasoundassisted extraction in the fractionation analysis of gravitation dust sediments," Microchimica Acta, vol. 163, no. 3-4, pp. 257-261, 2008.

[74] J. L. Raposo Jr., N. Ré-Poppi, and N. K. Honda, "Evaluation of concentration of some metal ions in different lichen species of the Sul-Mato-Grossense cerrado," Quimica Nova, vol. 30, no. 3, pp. 582-587, 2007.

[75] K. Mosetlha, N. Torto, and G. Wibetoe, "Determination of $\mathrm{Cu}$ and $\mathrm{Ni}$ in plants by microdialysis sampling: comparison of dialyzable metal fractions with total metal content," Talanta, vol. 71, no. 2, pp. 766-770, 2007.

[76] Y. Faiz, M. Tufail, M. T. Javed, M. M. Chaudhry, and NailaSiddique, "Road dust pollution of $\mathrm{Cd}, \mathrm{Cu}, \mathrm{Ni}, \mathrm{Pb}$ and Zn along Islamabad Expressway, Pakistan," Microchemical Journal, vol. 92, no. 2, pp. 186-192, 2009.

[77] A. Gáspár and H. Berndt, "Thermospray flame furnace atomic absorption spectrometry (TS-FF-AAS) - a simple method for trace element determination with microsamples in the $\mu \mathrm{g} / \mathrm{l}$ concentration range," Spectrochimica Acta, Part B, vol. 55 , no. 6 , pp. 587-597, 2000.

[78] J. Davies and H. Berndt, "Improvements in thermospray flame furnace atomic absorption spectrometry," Analytica Chimica Acta, vol. 479, no. 2, pp. 215-223, 2003.

[79] D. Schiavo, J. Y. Neira, and J. A. Nóbrega, "Direct determination of $\mathrm{Cd}, \mathrm{Cu}$ and $\mathrm{Pb}$ in wines and grape juices by thermospray flame furnace atomic absorption spectrometry," Talanta, vol. 76, no. 5, pp. 1113-1118, 2008.

[80] F. Rosini, C. C. Nascentes, J. Y. Neira, and J. A. Nóbrega, "Evaluation of selenium behavior in thermospray flame furnace atomic absorption spectrometry," Talanta, vol. 73, no. 5, pp. 845-849, 2007.

[81] K. Miranda, M. I. M. S. Bueno, and E. R. PereiraFilho, "Relevant information of concomitants obtained from background signal using thermospray flame furnace atomic absorption spectrometry (TS-FF-AAS) and chemometric tools," Journal of Analytical Atomic Spectrometry, vol. 24, no. 3, pp. 304-309, 2009.

[82] G. A. Petrucelli, P. K. Stocco, M. I. M. S. Bueno, and E. R. Pereira-Filho, "Tube atomizers in thermospray flame furnace atomic absorption spectrometry: Characterization using X-ray fluorescence, scanning electron microscopy and chemometrics," Journal of Analytical Atomic Spectrometry, vol. 21, no. 11, pp. 1298-1304, 2006.

[83] M. S. Gomes and E. Rodrigues Pereira-Filho, "Ti and $\mathrm{Ni}$ tubes combined in thermospray flame furnace atomic absorption spectrometry (TS-FF-AAS) for the determination of copper in biological samples," Microchemical Journal, vol. 93, no. 1, pp. 93-98, 2009.

[84] M. A. Z. Arruda and E. C. Figueiredo, "Atomic spectrometry based on metallic tube atomizers heated by flame: Innovative strategies from fundamentals to analysis," Spectrochimica Acta, vol. 64, no. 6, pp. 477-481, 2009.

[85] A. S. Ribeiro, D. L. Gallindo Borges, M. A. Vieira, and A. J. Curtius, "Coupling of ultrasonic nebulization to flame furnace atomic absorption spectrometry-new possibilities for trace element determination," Microchemical Journal, vol. 85, no. 2, pp. 341-346, 2007.

[86] P. Wu, R. Liu, H. Berndt, Y. Lv, and X. Hou, "Highly sensitive pneumatic nebulization flame furnace atomic absorption spectrometry: complete sample aerosol introduction and online preconcentration of cadmium by atom trap," Journal of Analytical Atomic Spectrometry, vol. 23, no. 1, pp. 37-42, 2007.
[87] P. Wu, Y. Gao, G. Cheng, W. Yang, Y. Lv, and X. Hou, "Selective determination of trace amounts of silver in complicated matrices by displacement-cloud point extraction coupled with thermospray flame furnace atomic absorption spectrometry," Journal of Analytical Atomic Spectrometry, vol. 23, no. 5, pp. 752-757, 2008.

[88] X. Wen, P. Wu, K. Xu, J. Wang, and X. Hou, "On-line precipitation-dissolution in knotted reactor for thermospray flame furnace AAS for determination of ultratrace cadmium," Microchemical Journal, vol. 91, no. 2, pp. 193-196, 2009.

[89] K. Miranda and E. R. Pereira-Filho, "Potentialities of thermospray flame furnace atomic absorption spectrometry (TS-FFAAS) in the fast sequential determination of $\mathrm{Cd}, \mathrm{Cu}, \mathrm{Pb}$ and Zn," Analytical Methods, vol. 1, no. 3, pp. 215-219, 2009.

[90] M. A. Bezerra, V. A. Lemos, J. S. Garcia, D. G. Da Silva, A. S. Araújo, and M. A. Z. Arruda, "Thermospray generation directly into a flame furnace-An alternative to improve the detection power in atomic absorption spectrometry," Talanta, vol. 82, no. 2, pp. 437-443, 2010.

[91] H. Matusiewicz and M. Krawczyk, "Determination of cadmium and lead in reference materials by volatile species generation with in situ trapping flame atomic absorption spectrometry," Microchemical Journal, vol. 83, no. 1, pp. 1723, 2006.

[92] H. Matusiewicz and M. Krawczyk, "Hydride generationin situ trapping-flame atomic absorption spectrometry hybridization for indium and thallium determination," Journal of the Brazilian Chemical Society, vol. 18, no. 2, pp. 304311, 2007.

[93] H. Matusiewicz and M. Krawczyk, "Determination of tellurium by hydride generation with in situ trapping flame atomic absorption spectrometry," Spectrochimica Acta, vol. 62, no. 3, pp. 309-316, 2007.

[94] H. Matusiewicz and M. Krawczyk, "Determination of total antimony and inorganic antimony species by hydride generation in situ trapping flame atomic absorption spectrometry: a new way to (ultra)trace speciation analysis," Journal of Analytical Atomic Spectrometry, vol. 23, no. 1, pp. 43-53, 2008.

[95] H. Matusiewicz and M. Krawczyk, "Determination of trace amounts of bismuth by in-situ trapping hydride generation flame atomic absorption spectrometry," Chemia Analityczna, vol. 52, no. 4, pp. 565-578, 2007.

[96] H. Matusiewicz and M. Krawczyk, "On-line hyphenation of hydride generation with in situ trapping flame atomic absorption spectrometry for arsenic and selenium determination," Analytical Sciences, vol. 22, no. 2, pp. 249-253, 2006.

[97] H. Matusiewicz and M. Krawczyk, "Determination of germanium and tin and inorganic tin species by hydride generation in situ trapping flame atomic absorption spectrometry," Analytical Letters, vol. 43, no. 16, pp. 2543-2562, 2010.

[98] H. Matusiewicz and M. Krawczyk, "Determination of total mercury by vapor generation in situ trapping flame atomic absorption spectrometry," Chemia Analityczna, vol. 53, no. 6, pp. 905-925, 2008.

[99] H. Matusiewicz and M. Krawczyk, "Sequential multi-element determination of hydride-forming elements (As, Bi, Cd, In, $\mathrm{Pb}, \mathrm{Se}, \mathrm{Te}, \mathrm{Tl}$ ) by high-resolution continuum source atom trapping-flame atomic absorption spectrometry," Chemia Analityczna, vol. 54, no. 5, pp. 949-973, 2009.

[100] H. Matusiewicz and M. Krawczyk, "Determination of nickel by chemical vapor generation in situ trapping flame AAS," Central European Journal of Chemistry, vol. 9, no. 4, pp. 648659, 2011. 
[101] N. Ertas, Z. Arslan, and J. F. Tyson, "Determination of lead by hydride generation atom trapping flame atomic absorption spectrometry," Journal of Analytical Atomic Spectrometry, vol. 23, no. 2, pp. 223-228, 2008.

[102] X. Wu, P. Wu, S. He, W. Yang, and X. Hou, "Improved performance of on-line atom trapping in flame furnace atomic absorption spectrometry by chemical vapor generation: determination of cadmium in high-salinity water samples," Spectroscopy Letters, vol. 42, no. 5, pp. 240-245, 2009.

[103] I. B. Karadjova, L. Lampugnani, J. Dědina, A. D’Ulivo, M. Onor, and D. L. Tsalev, "Organic solvents as interferents in arsenic determination by hydride generation atomic absorption spectrometry with flame atomization," Spectrochimica Acta, vol. 61, no. 5, pp. 525-531, 2006.

[104] M. B. B. Guerra, R. Carapelli, K. Miranda, A. R. Araujo Nogueira, and E. R. Pereira-Filho, "Determination of As and $\mathrm{Sb}$ in mineral waters by fast sequential continuous flow hydride generation atomic absorption spectrometry," Analytical Methods, vol. 3, no. 3, pp. 599-605, 2011.

[105] Q. O. Santos, C. G. Novaes, M. A. Bezerra et al., "Application of simplex optimization in the development of an automated online preconcentration system for manganese determination," Journal of the Brazilian Chemical Society, vol. 21, no. 12, pp. 2340-2346, 2010.

[106] M. Khajeh, A. R. Akbari Moghaddam, and E. Sanchooli, "Application of Doehlert design in the Optimization of microwave-assisted extraction for determination of zinc and copper in cereal samples using FAAS," Food Analytical Methods, vol. 3, no. 3, pp. 133-137, 2010.

[107] M. Khajeh and E. Sanchooli, "Optimization of microwaveassisted extraction procedure for zinc and iron determination in celery by Box-Behnken design," Food Analytical Methods, vol. 3, no. 2, pp. 75-79, 2010.

[108] F. S. Rojas, C. B. Ojeda, and J. M. C. Pavon, "Experimental design in the optimization of a microwave acid digestion procedure for the determination of metals in biomorphic ceramic samples by inductively coupled plasma mass spectrometry and atomic absorption spectrometry," Microchemical Journal, vol. 94, no. 1, pp. 7-13, 2010.

[109] S. Soriano, A. D. P. Netto, and R. J. Cassella, "Multivariate optimization of a microwave-assisted leaching procedure using dilute acid solutions, for FAAS determination of $\mathrm{Cu}$, $\mathrm{Fe}, \mathrm{Mn}$, and $\mathrm{Zn}$ in multivitamin/multimineral supplements," Analytical and Bioanalytical Chemistry, vol. 387, no. 3, pp. 1113-1120, 2007.

[110] M. A. Bezerra, J. T. Castro, R. C. Macedo, and D. G. da Silva, "Use of constrained mixture design for optimization of method for determination of zinc and manganese in tea leaves employing slurry sampling," Analytica Chimica Acta, vol. 670, no. 1-2, pp. 33-38, 2010.

[111] A. N. Anthemidis, I. S. I. Adam, and G. A. Zachariadis, "Poly(etheretherketone)-turnings a novel sorbent material for lead determination by flow injection flame atomic absorption spectrometry and factorial design optimization," Talanta, vol. 81, no. 3, pp. 996-1002, 2010.

[112] R. E. Santelli, M. D. Bezerra, O. D. de Santana, R. J. Cassella, and S. L. C. Ferreira, "Multivariate technique for optimization of digestion procedure by focussed microwave system for determination of $\mathrm{Mn}, \mathrm{Zn}$ and $\mathrm{Fe}$ in food samples using FAAS," Talanta, vol. 68, no. 4, pp. 1083-1088, 2006.

[113] E. Kenduzler, O. Yalcinkaya, S. Baytak, and A. R. Turker, "Application of full factorial design for the preconcentration of chromium by solid phase extraction with Amberlyst 36 resin," Microchimica Acta, vol. 160, no. 4, pp. 389-395, 2008.
[114] L. A. Portugal, H. S. Ferreira, W. N. L. dos Santos, and S. L. C. Ferreira, "Simultaneous pre-concentration procedure for the determination of cadmium and lead in drinking water employing sequential multi-element flame atomic absorption spectrometry," Microchemical Journal, vol. 87, no. 1, pp. 77-80, 2007.

[115] R. L. Dutra, H. F. Maltez, and E. Carasek, "Development of an on-line preconcentration system for zinc determination in biological samples," Talanta, vol. 69, no. 2, pp. 488-493, 2006.

[116] H. S. Ferreira, A. C. N. Santos, L. A. Portugal, A. C. S. Costa, M. Miró, and S. L. C. Ferreira, "Pre-concentration procedure for determination of copper and zinc in food samples by sequential multi-element flame atomic absorption spectrometry," Talanta, vol. 77, no. 1, pp. 73-76, 2008.

[117] A. Moreda-Piñeiro, P. Bermejo-Barrera, and A. BermejoBarrera, "Chemometric investigation of systematic error in the analysis of biological materials by flame and electrothermal atomic absorption spectrometry," Analytica Chimica Acta, vol. 560, no. 1-2, pp. 143-152, 2006.

[118] V. R. Amorim, W. L. Polito, and J. A. Gomes Neto, "Comparative studies of the sample decomposition of green and roasted coffee for determination of nutrients and data exploratory analysis," Journal of the Brazilian Chemical Society, vol. 18, no. 1, pp. 47-53, 2007.

[119] M. Madejczyk and D. Baralkiewicz, "Characterization of Polish rape and honeydew honey according to their mineral contents using ICP-MS and F-AAS/AES," Analytica Chimica Acta, vol. 617, no. 1-2, pp. 11-17, 2008.

[120] J. S. Santos, M. L. P. Santos, and M. M. Conti, "Comparative study of metal contents in Brazilian coffees cultivated by conventional and organic agriculture applying principal component analysis," Journal of the Brazilian Chemical Society, vol. 21, no. 8, pp. 1468-1476, 2010.

[121] I. N. Pasias, E. G. Farmaki, N. S. Thomaidis, and E. A. Piperaki, "Elemental content and total antioxidant activity of Salvia fruticosa," Food Analytical Methods, vol. 3, no. 3, pp. 195-204, 2010.

[122] Y. Wang, F. Feng, and Z. Wang, "Determination of selected elements in aqueous extractions of a traditional Chinese medicine formula by ICP-MS and FAAS: Evaluation of formula rationality," Analytical Letters, vol. 43, no. 6, pp. 983992, 2010.

[123] http://media.iupac.org/publications/pac/2000/.

[124] B. Michalke, "Element speciation definitions, analytical methodology, and some examples," Ecotoxicology and Environmental Safety, vol. 56, no. 1, pp. 122-139, 2003.

[125] J. Bettmer, "Elemental speciation," Analytical and Bioanalytical Chemistry, vol. 372, no. 1, pp. 33-34, 2002.

[126] F. Pena-Pereira, I. Lavilla, and C. Bendicho, "Miniaturized preconcentration methods based on liquid-liquid extraction and their application in inorganic ultratrace analysis and speciation: a review," Spectrochimica Acta, vol. 64, no. 1, pp. $1-15,2009$.

[127] P. Hemmatkhah, A. Bidari, S. Jafarvand, M. R. M. Hosseini, and Y. Assadi, "Speciation of chromium in water samples using dispersive liquid-liquid microextraction and flame atomic absorption spectrometry," Microchimica Acta, vol. 166, no. 1-2, pp. 69-75, 2009.

[128] S. Tokalioğlu, S. Arsav, A. Delibaş, and C. Soykan, "Indirect speciation of $\mathrm{Cr}(\mathrm{III})$ and $\mathrm{Cr}(\mathrm{VI})$ in water samples by selective separation and preconcentration on a newly synthesized chelating resin," Analytica Chimica Acta, vol. 645, no. 1-2, pp. 36-41, 2009. 
[129] X. Long, M. Miró, and E. H. Hansen, "On-line dynamic extraction and automated determination of readily bioavailable hexavalent chromium in solid substrates using microsequential injection bead-injection lab-on-valve hyphenated with electrothermal atomic absorption spectrometry," Analyst, vol. 131, no. 1, pp. 132-140, 2006.

[130] Y. Tian, M. L. Chen, X. W. Chen et al., "Arsenic preconcentration via solid phase extraction and speciation by HPLC-gradient hydride generation atomic absorption spectrometry," Journal of Analytical Atomic Spectrometry, vol. 26, no. 1, pp. 133-140, 2011.

[131] S. Saçmaci and Ş. Kartal, "Selective extraction, separation and speciation of iron in different samples using 4-acetyl-5methyl-1-phenyl-1H-pyrazole-3-carboxylic acid," Analytica Chimica Acta, vol. 623, no. 1, pp. 46-52, 2008.

[132] A. N. Anthemidis and S. J. V. Koussoroplis, "Determination of chromium(VI) and lead in water samples by on-line sorption preconcentration coupled with flame atomic absorption spectrometry using a PCTFE-beads packed column," Talanta, vol. 71, no. 4, pp. 1728-1733, 2007.

[133] R. P. Monasterio, J. C. Altamirano, L. D. Martínez, and R. G. Wuilloud, "A novel fiber-packed column for on-line preconcentration and speciation analysis of chromium in drinking water with flame atomic absorption spectrometry," Talanta, vol. 77, no. 4, pp. 1290-1294, 2009.

[134] V. N. Bulut, D. Ozdes, O. Bekircan, A. Gundogdu, C. Duran, and M. Soylak, "Carrier element-free coprecipitation (CEFC) method for the separation, preconcentration and speciation of chromium using an isatin derivative," Analytica Chimica Acta, vol. 632, no. 1, pp. 35-41, 2009.

[135] M. A. Z. Arruda, Ed., Trends in Sample Preparation, Nova Science, New York, NY, USA, 2007.

[136] B. Welz and M. Sperling, Atomic Absorption Spectrometry, Wiley-VCH, Weinheim, Germany, 1999.

[137] R. F. Browner, A. W. Boorn, and D. D. Smith, "Aerosol transport model for atomic spectrometry," Analytical Chemistry, vol. 54, no. 8, pp. 1411-1419, 1982.

[138] N. M. Najafi, P. Shakeri, and E. Ghasemi, "Separation and Preconcentration of Ultra Traces of Some Heavy Metals in Environmental Samples by Electrodeposition Technique Prior to Flame Atomic Absorption Spectroscopy Determination (ED-FAAS)," Scientia Iranica Transaction C, vol. 17, no. 2, pp. 144-151, 2010.

[139] D. L. Giokas, E. K. Paleologos, M. I. Prodromidis, and M. I. Karayannis, "Development of 1-(2-pyridylazo)-2-naphtholmodified polymeric membranes for the effective batch preconcentration and determination of zinc traces with flame atomic absorption spectrometry," Talanta, vol. 56, no. 3, pp. 491-498, 2002.

[140] S. Vellaichamy and K. Palanivelu, "Preconcentration and separation of copper, nickel and zinc in aqueous samples by flame atomic absorption spectrometry after column solid-phase extraction onto MWCNTs impregnated with D2EHPA-TOPO mixture," Journal of Hazardous Materials, vol. 185, no. 2-3, pp. 1131-1139, 2011.

[141] V. A. Lemos, J. S. Santos, and P. X. Baliza, "Me-BTABr reagent in cloud point extraction for spectrometric determination of copper in water samples," Journal of the Brazilian Chemical Society, vol. 17, no. 1, pp. 30-35, 2006.

[142] F. Shemirani, R. R. Kozani, and Y. Assadi, "Development of a cloud point extraction and preconcentration method for silver prior to flame atomic absorption spectrometry," Microchimica Acta, vol. 157, no. 1-2, pp. 81-85, 2007.
[143] Y. Surme, I. Narin, M. Soylak, H. Yuruk, and M. Dogan, "Cloud point extraction procedure for flame atomic absorption spectrometric determination of lead(II) in sediment and water samples," Microchimica Acta, vol. 157, no. 3-4, pp. 193199, 2007.

[144] S. G. Silva, P. V. Oliveira, J. A. Nóbrega, and F. R. P. Rocha, "Cloud point extraction to avoid interferences by structured background on nickel determination in plant materials by FAAS," Analytical Methods, vol. 1, no. 1, pp. 68-70, 2009.

[145] N. Baghban, A. M. H. Shabani, S. Dadfarnia, and A. A. Jafari, "Flame atomic absorption spectrometric determination of trace amounts of cobalt after cloud point extraction as 2[(2-mercaptophenylimino)methyl]phenol complex," Journal of the Brazilian Chemical Society, vol. 20, no. 5, pp. 832-838, 2009.

[146] V. A. Lemos and G. T. David, "An on-line cloud point extraction system for flame atomic absorption spectrometric determination of trace manganese in food samples," Microchemical Journal, vol. 94, no. 1, pp. 42-47, 2010.

[147] T. G. Kazi, S. Khan, J. A. Baig, N. F. Kolachi, H. I. Afridi, and A. Q. Shah, "Determination of trace quantity of aluminium in dialysate concentrates using solid phase and cloud point extraction methods," Analytical Methods, vol. 2, no. 5, pp. 558-563, 2010.

[148] S. G. Silva, P. V. Oliveira, and F. R. P. Rocha, "A green analytical procedure for determination of copper and iron in plant materials after cloud point extraction," Journal of the Brazilian Chemical Society, vol. 21, no. 2, pp. 234-239, 2010.

[149] Z. Sun and P. Liang, "Determination of $\mathrm{Cr}$ (III) and total chromium in water samples by cloud point extraction and flame atomic absorption spectrometry," Microchimica Acta, vol. 162, no. 1-2, pp. 121-125, 2008.

[150] H. Filik, Z. Yanaz, and R. Apak, "Selective determination of total vanadium in water samples by cloud point extraction of its ternary complex," Analytica Chimica Acta, vol. 620, no. 1-2, pp. 27-33, 2008.

[151] H. Watanabe and H. Tanaka, "A non-ionic surfactant as a new solvent for liquid-liquid extraction of zinc(II) with 1(2-pyridylazo)-2-naphthol," Talanta, vol. 25, no. 10, pp. 585$589,1978$.

[152] F. H. Quina and W. L. Hinze, "Surfactant-mediated cloud point extractions: An environmentally benign alternative separation approach," Industrial and Engineering Chemistry Research, vol. 38, no. 11, pp. 4150-4168, 1999.

[153] E. K. Paleologos, D. L. Giokas, and M. I. Karayannis, "Micelle-mediated separation and cloud-point extraction," Trends in Analytical Chemistry, vol. 24, no. 5, pp. 426-436, 2005.

[154] M. A. Bezerra, M. A. Z. Arruda, and S. L. C. Ferreira, "Cloud point extraction as a procedure of separation and pre-concentration for metal determination using spectroanalytical techniques: A review," Applied Spectroscopy Reviews, vol. 40, no. 4, pp. 269-299, 2005.

[155] P. Wu, Y. Zhang, Y. Lv, and X. Hou, "Cloud point extractionthermospray flame quartz furnace atomic absorption spectrometry for determination of ultratrace cadmium in water and urine," Spectrochimica Acta, vol. 61, no. 12, pp. 13101314, 2006.

[156] G. L. Donati, C. C. Nascentes, A. R. A. Nogueira, M. A. Z. Arruda, and J. A. Nóbrega, "Acid extraction and cloud point preconcentration as sample preparation strategies for cobalt determination in biological materials by thermospray flame furnace atomic absorption spectrometry," Microchemical Journal, vol. 82, no. 2, pp. 189-195, 2006. 
[157] J. Lu, J. Tian, H. Wu, and C. Zhao, "Speciation determination of chromium(VI) and chromium(III) in soil samples after cloud point extraction," Analytical Letters, vol. 42, no. 11, pp. 1662-1677, 2009.

[158] S. Candir, I. Narin, and M. Soylak, "Ligandless cloud point extraction of $\mathrm{Cr}(\mathrm{III}), \mathrm{Pb}(\mathrm{II}), \mathrm{Cu}(\mathrm{II}), \mathrm{Ni}(\mathrm{II}), \mathrm{Bi}(\mathrm{III})$, and $\mathrm{Cd}(\mathrm{II})$ ions in environmental samples with Tween 80 and flame atomic absorption spectrometric determination," Talanta, vol. 77, no. 1, pp. 289-293, 2008.

[159] V. A. Lemos, P. X. Baliza, A. L. Carvalho, R. V. Oliveira, L. S. G. Teixeira, and M. A. Bezerra, "Development of a new sequential injection in-line cloud point extraction system for flame atomic absorption spectrometric determination of manganese in food samples," Talanta, vol. 77, no. 1, pp. 388393, 2008.

[160] D. Kara, "Preconcentration and determination of trace metals by flow injection micelle-mediated extraction using flame atomic absorption spectrometry," Talanta, vol. 79, no. 2, pp. 429-435, 2009.

[161] M. B. Gholivand, A. Babakhanian, and E. Rafiee, "Determination of $\mathrm{Sn}(\mathrm{II})$ and $\mathrm{Sn}(\mathrm{IV})$ after mixed micelle-mediated cloud point extraction using $\alpha$-polyoxometalate as a complexing agent by flame atomic absorption spectrometry," Talanta, vol. 76, no. 3, pp. 503-508, 2008.

[162] G. D. Matos, E. B. Reis, A. C. S. Costa, and S. L. C. Ferreira, "Speciation of chromium in river water samples contaminated with leather effluents by flame atomic absorption spectrometry after separation/preconcentration by cloud point extraction," Microchemical Journal, vol. 92, no. 2, pp. 135-139, 2009.

[163] Y. Gao, P. Wu, W. Li, Y. Xuan, and X. Hou, "Simultaneous and selective preconcentration of trace $\mathrm{Cu}$ and $\mathrm{Ag}$ by one-step displacement cloud point extraction for FAAS determination," Talanta, vol. 81, no. 1-2, pp. 586-590, 2010.

[164] M. A. Bezerra and S. L. C. Ferreira, Extração em ponto nuvem: princípios em química analítica, Vitória da ConquistaBahia/Brasil: Editora Edições UESB, 2006.

[165] R. J. Soukup-Hein, M. M. Warnke, and D. W. Armstrong, "Ionic liquids in analytical chemistry," Annual Review of Analytical Chemistry, vol. 2, pp. 145-168, 2009.

[166] I. Krossing, J. M. Slattery, C. Daguenet, P. J. Dyson, A. Oleinikova, and H. Weingärtner, "Why are ionic liquids liquid? A simple explanation based on lattice and solvation energies," Journal of the American Chemical Society, vol. 128, no. 41, pp. 13427-13434, 2006.

[167] P. Sun and D. W. Armstrong, "Ionic liquids in analytical chemistry," Analytica Chimica Acta, vol. 661, no. 1, pp. 1-16, 2010.

[168] E. M. Martinis, R. A. Olsina, J. C. Altamirano, and R. G. Wuilloud, "On-line ionic liquid-based preconcentration system coupled to flame atomic absorption spectrometry for trace cadmium determination in plastic food packaging materials," Talanta, vol. 78, no. 3, pp. 857-862, 2009.

[169] P. Liang and L. Peng, "Ionic liquid-modified silica as sorbent for preconcentration of cadmium prior to its determination by flame atomic absorption spectrometry in water samples," Talanta, vol. 81, no. 1-2, pp. 673-677, 2010.

[170] G. Fang, J. Zhang, J. Lu, L. Ma, and S. Wang, "Preparation, characterization, and application of a new thiolfunctionalized ionic liquid for highly selective extraction of Cd(II)," Microchimica Acta, vol. 171, no. 3, pp. 305-311, 2010.

[171] H. Bai, Q. Zhou, G. Xie, and J. Xiao, "Temperaturecontrolled ionic liquid-liquid-phase microextraction for the pre-concentration of lead from environmental samples prior to flame atomic absorption spectrometry," Talanta, vol. 80, no. 5, pp. 1638-1642, 2010.

[172] S. Mahpishanian and F. Shemirani, "Preconcentration procedure using in situ solvent formation microextraction in the presence of ionic liquid for cadmium determination in saline samples by flame atomic absorption spectrometry," Talanta, vol. 82, no. 2, pp. 471-476, 2010.

[173] N. Li, G. Fang, B. Liu, J. Zhang, L. Zhao, and S. Wang, "A novel hydrophobic task specific ionic liquid for the extraction of Cd(II) from water and food samples as applied to AAS determination," Analytical Sciences, vol. 26, no. 4, pp. 455459, 2010.

[174] S. Dadfarnia, A. M. H. Shabani, M. S. Bidabadi, and A. A. Jafari, "A novel ionic liquid/micro-volume back extraction procedure combined with flame atomic absorption spectrometry for determination of trace nickel in samples of nutritional interest," Journal of Hazardous Materials, vol. 173, no. 1-3, pp. 534-538, 2010.

[175] S. R. Yousefi and F. Shemirani, "Development of a robust ionic liquid-based dispersive liquid-liquid microextraction against high concentration of salt for preconcentration of trace metals in saline aqueous samples: Application to the determination of $\mathrm{Pb}$ and $\mathrm{Cd}, "$ Analytica Chimica Acta, vol. 669, no. 1-2, pp. 25-31, 2010.

[176] H. Abdolmohammad-Zadeh and G. H. Sadeghi, "A novel microextraction technique based on 1-hexylpyridinium hexafluorophosphate ionic liquid for the preconcentration of zinc in water and milk samples," Analytica Chimica Acta, vol. 649, no. 2, pp. 211-217, 2009.

[177] V. Camel, "Solid phase extraction of trace elements," Spectrochimica Acta - Part B Atomic Spectroscopy, vol. 58, no. 7, pp. 1177-1233, 2003.

[178] A. F. Barbosa, M. G. Segatelli, A. C. Pereira et al., "Solidphase extraction system for $\mathrm{Pb}$ (II) ions enrichment based on multiwall carbon nanotubes coupled on-line to flame atomic absorption spectrometry," Talanta, vol. 71, no. 4, pp. 15121519, 2007.

[179] Ş. Tokalıŏlu and Ş. Kartal, "Synthesis and application of a new chelating resin functionalized with salicylaldoxime for the determination of $\mathrm{Pb}(\mathrm{II}), \mathrm{Ni}(\mathrm{II}), \mathrm{Cu}(\mathrm{II})$ and $\mathrm{Mn}(\mathrm{II})$ ions in water samples by flame atomic absorption spectrometry," Microchimica Acta, vol. 162, no. 1-2, pp. 87-92, 2008.

[180] C. R. T. Tarley, W. N. L. Dos Santos, C. M. Dos Santos, S. L. C. Ferreira, and M. A. Z. Arruda, "Factorial design and doehlert matrix in optimization of flow system for preconcentration of copper on polyurethane foam loaded with 4-(2-pyridylazo)-resorcinol," Analytical Letters, vol. 37, no. 7, pp. 1437-1455, 2004.

[181] R. S. Praveen, S. Daniel, and T. P. Rao, "Solid phase extraction preconcentration of cobalt and nickel with 5,7-dichloroquinone-8-ol embedded styrene-ethylene glycol dimethacrylate polymer particles and determination by flame atomic absorption spectrometry (FAAS)," Talanta, vol. 66, no. 2, pp. 513-520, 2005.

[182] M. A. Chamjangali, L. Sharif-Razavian, B. Bahramian, and G. Bagherian, "Synthesis and application of a functionalized polystyrene resin for on-line preconcentration and determination of cobalt(II) in water samples by flow injection/FAAS," Journal of the Brazilian Chemical Society, vol. 21, no. 3, pp. 525-532, 2010.

[183] V. A. Lemos, A. S. Dos Passos, G. S. Novaes, D. A. Santana, A. L. De Carvalho, and D. G. Da Silva, "Determination of cobalt, copper and nickel in food samples after pre-concentration 
on a new pyrocatechol-functionalized polyurethane foam sorbent," Reactive and Functional Polymers, vol. 67, no. 6, pp. 573-581, 2007.

[184] M. A. Chamjangali, S. T. Farooji, and B. Bahramian, "Application of chloromethylated polystyrene functionalized with N,N-bis(naphthylideneimino)diethylenetriamine in an on-line preconcentration system for the determination of cadmium by FAAS," Journal of Hazardous Materials, vol. 174, no. $1-3$, pp. 843-850, 2010.

[185] A. Efendioğlu, M. Y. Aşci, and B. Bati, "Preconcentration of $\mathrm{Cu}(\mathrm{II}), \mathrm{Cd}(\mathrm{II})$ and $\mathrm{Pb}(\mathrm{II})$ on amberlite $\mathrm{XAD}-4$ resin functionalized with $\mathrm{N}, \mathrm{N}$-Bis(o-vanillinidene)-ethylenediamine and their determination by FAAs in water samples," Analytical Sciences, vol. 26, no. 12, pp. 1283-1288, 2010.

[186] V. A. Lemos, C. G. Novaes, A. S. Lima, and D. R. Vieira, "Flow injection preconcentration system using a new functionalized resin for determination of cadmium and nickel in tobacco samples," Journal of Hazardous Materials, vol. 155, no. 1-2, pp. 128-134, 2008.

[187] Ş. Tokalığlu, H. Büyükbaş, and Ş. Kartal, "Preconcentration of trace elements by using 1-(2-pyridylazo)-2-naphthol functionalized amberlite XAD-1180 resin and their determination by FAAS," Journal of the Brazilian Chemical Society, vol. 17, no. 1, pp. 98-106, 2006.

[188] M. S. Hosseini, H. Raissi, and S. Madarshahian, "Synthesis and application of a new chelating resin functionalized with 2,3-dihydroxy benzoic acid for Fe(III) determination in water samples by flame atomic absorption spectrometry," Reactive and Functional Polymers, vol. 66, no. 12, pp. 1539-1545, 2006.

[189] D. Kara, A. Fisher, and S. J. Hill, "Determination of trace heavy metals in soil and sediments by atomic spectrometry following preconcentration with Schiff bases on Amberlite XAD-4," Journal of Hazardous Materials, vol. 165, no. 1-3, pp. 1165-1169, 2009.

[190] V. A. Lemos, E. M. Gama, and A. Da Silva Lima, "On-line preconcentration and determination of cadmium, cobalt and nickel in food samples by flame atomic absorption spectrometry using a new functionalized resin," Microchimica Acta, vol. 153, no. 3-4, pp. 179-186, 2006.

[191] G. Venkatesh and A. K. Singh, "Enrichment and flame atomic absorption spectrometric determination of palladium using chelating matrices designed by functionalizing Amberlite XAD-2/16 and silica gel," Microchimica Acta, vol. 159, no. 12, pp. 149-155, 2007.

[192] T. C. Ávila, M. G. Segatelli, L. A. Beijo, and C. R. T. Tarley, "Employ of silica gel organically modified and ionically imprinted for selective on-line preconcentration of copperions," Quimica Nova, vol. 33, no. 2, pp. 301-308, 2010.

[193] E. Birlik, A. Ersöz, A. Denizli, and R. Say, "Preconcentration of copper using double-imprinted polymer via solid phase extraction," Analytica Chimica Acta, vol. 565, no. 2, pp. 145 $151,2006$.

[194] T. P. Rao, R. Kala, and S. Daniel, "Metal ion-imprinted polymers-Novel materials for selective recognition of inorganics," Analytica Chimica Acta, vol. 578, no. 2, pp. 105-116, 2006.

[195] M. G. Segatelli, V. S. Santos, A. B. T. Presotto, I. V. P. Yoshida, and C. R. T. Tarley, "Cadmium ion-selective sorbent preconcentration method using ion imprinted poly(ethylene glycol dimethacrylate-co-vinylimidazole)," Reactive and Functional Polymers, vol. 70, no. 6, pp. 325-333, 2010.

[196] S. Walas, A. Tobiasz, M. Gawin, B. Trzewik, M. Strojny, and H. Mrowiec, "Application of a metal ion-imprinted polymer based on salen-Cu complex to flow injection preconcentra- tion and FAAS determination of copper," Talanta, vol. 76, no. 1, pp. 96-101, 2008

[197] M. Gawin, J. Konefał, B. Trzewik et al., "Preparation of a new $\mathrm{Cd}(\mathrm{II})$-imprinted polymer and its application to determination of cadmium(II) via flow-injection-flame atomic absorption spectrometry," Talanta, vol. 80, no. 3, pp. 13051310, 2010.

[198] R. S. Praveen, G. R. K. Naidu, and T. P. Rao, "Dithiocarbamate functionalized or surface sorbed Merrifield resin beads as column materials for on line flow injection-flame atomic absorption spectrometry determination of lead," Analytica Chimica Acta, vol. 600, no. 1-2, pp. 205-213, 2007.

[199] S. Meesri, N. Praphairaksit, and A. Imyim, "Extraction and preconcentration of toxic metal ions from aqueous solution using benzothiazole-based chelating resins," Microchemical Journal, vol. 87, no. 1, pp. 47-55, 2007.

[200] R. P. Monasterio and R. G. Wuilloud, "Trace level determination of cadmium in wine by on-line preconcentration in a 5-Br-PADAP functionalized wool-packed microcolumn coupled to flame atomic absorption spectrometry," Talanta, vol. 79, no. 5, pp. 1484-1488, 2009.

[201] R. M. Cespón-Romero and M. C. Yebra-Biurrun, "Determination of trace metals in urine with an on-line ultrasoundassisted digestion system combined with a flow-injection preconcentration manifold coupled to flame atomic absorption spectrometry," Analytica Chimica Acta, vol. 609, no. 2, pp. 184-191, 2008.

[202] S. Wang and R. Zhang, "Selective solid-phase extraction of trace copper ions in aqueous solution with a $\mathrm{Cu}$ (II)imprinted interpenetrating polymer network gel prepared by ionic imprinted polymer (IIP) technique," Microchimica Acta, vol. 154, no. 1-2, pp. 73-80, 2006.

[203] Ç. A. Şahin and I. Tokgöz, "A novel solidified floating organic drop microextraction method for preconcentration and determination of copper ions by flow injection flame atomic absorption spectrometry," Analytica Chimica Acta, vol. 667 , no. $1-2$, pp. 83-87, 2010.

[204] M. Mohamadi and A. Mostafavi, "A novel solidified floating organic drop microextraction based on ultrasounddispersion for separation and preconcentration of palladium in aqueous samples," Talanta, vol. 81, no. 1-2, pp. 309-313, 2010.

[205] S. Dadfarnia, A. M. H. Shabani, and E. Kamranzadeh, "Separation/preconcentration and determination of cadmium ions by solidification of floating organic drop microextraction and FI-AAS," Talanta, vol. 79, no. 4, pp. 1061-1065, 2009.

[206] J. Ma, J. Zhang, X. Du, and X. Lei, "Solidified floating organic drop microextraction for determination of trace amounts of zinc in water samples by flame atomic absorption spectrometry," Microchimica Acta, vol. 168, no. 1-2, pp. 153159, 2010.

[207] M. A. Jeannot and F. F. Cantwell, "Solvent microextraction into a single drop," Analytical Chemistry, vol. 68, no. 13, pp. 2236-2240, 1996.

[208] K. Uezu, H. Nakamura, J. I. Kanno, T. Sugo, M. Goto, and F. Nakashio, "Metal ion-imprinted polymer prepared by the combination of surface template polymerization with postirradiation by $\gamma$-rays," Macromolecules, vol. 30, no. 13, pp. 3888-3891, 1997.

[209] A. Tobiasz, S. Walas, B. Trzewik et al., "Cu(II)-imprinted styrene-divinylbenzene beads as a new sorbent for flow injection-flame atomic absorption determination of copper," Microchemical Journal, vol. 93, no. 1, pp. 87-92, 2009. 
[210] M. Hiraide, T. Ito, M. Baba, H. Kawaguchi, and A. Mizuike, "Multielement preconcentration of trace heavy metals in water by coprecipitation and flotation with indium hydroxide for Inductively Coupled Plasma Atomic Emission Spectrometry," Analytical Chemistry, vol. 52, no. 6, pp. 804807, 1980.

[211] M. Ghaedi, A. Shokrollahi, and M. Montazerozohori, "Development of a flotation method for preconcentrationseparation of trace amounts of some metal ions in plant tissues prior to their FAAS determinations," Quimica Nova, vol. 33, no. 2, pp. 404-410, 2010.

[212] S. Dadfarnia, A. M. H. Shabani, and Z. Dehghani, "Immobilized stearic acid as a new sorbent for on-line preconcentration and determination of lead by flow injection flame atomic absorption spectrometry," Journal of the Brazilian Chemical Society, vol. 17, no. 3, pp. 548-554, 2006.

[213] A. Stafiej and K. Pyrzynska, "Solid phase extraction of metal ions using carbon nanotubes," Microchemical Journal, vol. 89, no. 1, pp. 29-33, 2008.

[214] S. Özdemir, R. Gul-Guven, E. Kilinc, M. Dogru, and S. Erdogan, "Preconcentration of cadmium and nickel using the bioadsorbent Geobacillus thermoleovorans subsp. stromboliensis immobilized on Amberlite XAD-4," Microchimica Acta, vol. 169, no. 1, pp. 79-85, 2010.

[215] S. Rastegarzadeh, N. Pourreza, A. Kiasat, and H. Yahyavi, "Selective solid phase extraction of palladium by adsorption of its 5(p-dimethylaminobenzylidene)rhodanine complex on silica-PEG as a new adsorbent," Microchimica Acta, vol. 170, no. 1, pp. 135-140, 2010.

[216] D. Pérez-Quintanilla, A. Sánchez, I. del Hierro, M. Fajardo, and I. Sierra, "Solid phase extraction of $\mathrm{Pb}(\mathrm{II})$ in water samples using a new hybrid inorganic-organic mesoporous silica prior to its determination by FAAS," Microchimica Acta, vol. 165, no. 3-4, pp. 291-298, 2009.

[217] S. Ghaseminezhad, D. Afzali, and M. A. Taher, "Flame atomic absorption spectrometry for the determination of trace amount of rhodium after separation and preconcentration onto modified multiwalled carbon nanotubes as a new solid sorbent," Talanta, vol. 80, no. 1, pp. 168-172, 2009.

[218] P. Liang, E. Zhao, Q. Ding, and D. Du, "Multiwalled carbon nanotubes microcolumn preconcentration and determination of gold in geological and water samples by flame atomic absorption spectrometry," Spectrochimica Acta, vol. 63, no. 6, pp. 714-717, 2008.

[219] X. Zhao, N. Song, Q. Jia, and W. Zhou, "Determination of $\mathrm{Cu}, \mathrm{Zn}, \mathrm{Mn}$, and $\mathrm{Pb}$ by microcoluMn packed with multiwalled carbon nanotubes on-line coupled with flame atomic absorption spectrometry," Microchimica Acta, vol. 166, no. 3-4, pp. 329-335, 2009.

[220] R. S. Amais, J. S. Ribeiro, M. G. Segatelli, I. V. P. Yoshida, P. O. Luccas, and C. R. T. Tarley, "Assessment of nanocomposite alumina supported on multi-wall carbon nanotubes as sorbent for on-line nickel preconcentration in water samples," Separation and Purification Technology, vol. 58, no. 1, pp. 122-128, 2007.

[221] D. Afzali, A. Mostafavi, M. A. Taher, and A. Moradian, "Flame atomic absorption spectrometry determination of trace amounts of copper after separation and preconcentration onto TDMBAC-treated analcime pyrocatecholimmobilized," Talanta, vol. 71, no. 2, pp. 971-975, 2007.

[222] A. P. Anjos, L. Cornejo-Ponce, S. Cadore, and N. Baccan, "Determination of manganese by flame atomic absorption spectrometry after its adsorption onto naphthalene modified with 1-(2-pyridylazo)-2-naphthol (PAN)," Talanta, vol. 71, no. 3, pp. 1252-1256, 2007.

[223] A. N. Anthemidis and K. I. G. Ioannou, "Evaluation of polychlorotrifluoroethylene as sorbent material for on-line solid phase extraction systems: Determination of copper and lead by flame atomic absorption spectrometry in water samples," Analytica Chimica Acta, vol. 575, no. 1, pp. 126132, 2006.

[224] J. S. Carletto, R. M. Luciano, G. C. Bedendo, and E. Carasek, "Simple hollow fiber renewal liquid membrane extraction method for pre-concentration of $\mathrm{Cd}(\mathrm{II})$ in environmental samples and detection by Flame Atomic Absorption Spectrometry," Analytica Chimica Acta, vol. 638, no. 1, pp. 45-50, 2009.

[225] A. A. Ensafi and A. Z. Shiraz, "Combination of solid phase extraction and flame atomic absorption spectrometry for trace analysis of cadmium," Journal of the Brazilian Chemical Society, vol. 19, no. 1, pp. 11-17, 2008.

[226] A. R. Farahmand, S. Yousefi, N. Fumani, S. Mirza, M. Shamsipur, and J. Hassan, "Preconcentration of beryllium via octadecyl silica gel microparticles doped with aluminon, and its determination by flame atomic absorption spectrometry," Microchimica Acta, vol. 166, no. 1-2, pp. 89-94, 2009.

[227] R. Gong, Y. Hu, J. Chen, F. Chen, and Z. Liu, "A cellulosebased carboxyl cotton chelator having citric acid as an anchored ligand: preparation and application as solid phase extractant for copper determination by flame atomic absorption spectrometry," Microchimica Acta, vol. 158, no. 3-4, pp. 315-320, 2007.

[228] A. P. S. Gonzáles, M. A. Firmino, C. S. Nomura, F. R. P. Rocha, P. V. Oliveira, and I. Gaubeur, "Peat as a natural solid-phase for copper preconcentration and determination in a multicommuted flow system coupled to flame atomic absorption spectrometry," Analytica Chimica Acta, vol. 636, no. 2, pp. 198-204, 2009.

[229] E. Kendüzler, A. R. Türker, and O. Yalçinkaya, "Separation and preconcentration of trace manganese from various samples with Amberlyst 36 column and determination by flame atomic absorption spectrometry," Talanta, vol. 69, no. 4, pp. 835-840, 2006.

[230] M. Karve and R. V. Rajgor, "Octadecyl bonded silica membrane disk modified with cyanex302 for preconcentration and determination of traces of cobalt in urine by flame atomic absorption spectrometry," Analytical Letters, vol. 42, no. 16, pp. 2520-2532, 2009.

[231] V. A. Lemos, D. Gonçalves da Silva, A. Lago de Carvalho, D. de Andrade Santana, G. dos Santos Novaes, and A. Souza dos Passos, "Synthesis of amberlite XAD-2-PC resin for preconcentration and determination of trace elements in food samples by flame atomic absorption spectrometry," Microchemical Journal, vol. 84, no. 1-2, pp. 14-21, 2006.

[232] H. D. Liang and D. M. Han, "Multi-walled carbon nanotubes as sorbent for flow injection on-line microcolumn preconcentration coupled with flame atomic absorption spectrometry for determination of cadmium and copper," Analytical Letters, vol. 39, no. 11, pp. 2285-2295, 2006.

[233] Y. Liu, Y. Guo, S. Meng, F. Feng, and X. Chang, "Determination of trace heavy metals in waters by flame atomic absorption spectrometry after preconcentration with 2,4dinitrophenyldiazoaminoazobenzene on Amberlite XAD-2," Microchimica Acta, vol. 157, no. 3-4, pp. 209-214, 2007.

[234] Y. Liu, Y. Guo, S. Meng, and X. Chang, "Online separation and preconcentration of trace heavy metals with 
2,6-dihydroxyphenyl-diazoaminoazobenzene impregnated amberlite XAD-4," Microchimica Acta, vol. 158, no. 3-4, pp. 239-245, 2007.

[235] R. Liu and P. Liang, "Determination of gold by nanometer titanium dioxide immobilized on silica gel packed microcolumn and flame atomic absorption spectrometry in geological and water samples," Analytica Chimica Acta, vol. 604, no. 2, pp. 114-118, 2007.

[236] J. J. Ma, X. Du, J. W. Zhang, J. C. Li, and L. Z. Wang, "Ultrasound-assisted emulsification-microextraction combined with flame atomic absorption spectrometry for determination of trace cadmium in water samples," Talanta, vol. 80, no. 2, pp. 980-984, 2009.

[237] M. G. Martino, G. T. MacArovscha, and S. Cadore, "The use of Zincon for preconcentration and determination of Zinc by flame atomic absorption spectrometry," Analytical Methods, vol. 2, no. 9, pp. 1258-1262, 2010.

[238] M. H. Mashhadizadeh, M. Pesteh, M. Talakesh, I. Sheikhshoaie, M. M. Ardakani, and M. A. Karimi, "Solid phase extraction of copper (II) by sorption on octadecyl silica membrane disk modified with a new Schiff base and determination with atomic absorption spectrometry," Spectrochimica Acta, vol. 63, no. 8, pp. 885-888, 2008.

[239] M. H. Mashhadizadeh, M. S. Azimi, M. Pesteh, I. Sheikhshoaei, M. M. Ardakani, and M. A. Karimi, "Flame atomic absorption spectrometric determination of $\mu \mathrm{g}$ amounts of Fe (III) ions after solid phase extraction using modified octadecyl silica membrane disks," Spectrochimica Acta, vol. 63, no. 8, pp. 889-892, 2008.

[240] E. Melek, M. Tuzen, and M. Soylak, "Flame atomic absorption spectrometric determination of cadmium(II) and lead(II) after their solid phase extraction as dibenzyldithiocarbamate chelates on Dowex Optipore V-493," Analytica Chimica Acta, vol. 578, no. 2, pp. 213-219, 2006.

[241] S. Z. Mohammadi, D. Afzali, M. A. Taher, and Y. M. Baghelani, "Ligandless dispersive liquid-liquid microextraction for the separation of trace amounts of silver ions in water samples and flame atomic absorption spectrometry determination," Talanta, vol. 80, no. 2, pp. 875-879, 2009.

[242] S. Mohammadi, D. Afzali, M. Taher, and Y. Baghelani, "Determination of trace amounts of palladium by flame atomic absorption spectrometry after ligandless-dispersive liquid-liquid microextraction," Microchimica Acta, vol. 168, no. 1-2, pp. 123-128, 2010.

[243] W. Ngeontae, W. Aeungmaitrepirom, T. Tuntulani, and A. Imyim, "Highly selective preconcentration of $\mathrm{Cu}(\mathrm{II})$ from seawater and water samples using amidoamidoxime silica," Talanta, vol. 78, no. 3, pp. 1004-1010, 2009.

[244] N. Pourreza, J. Zolgharnein, A. R. Kiasat, and T. Dastyar, "Silica gel-polyethylene glycol as a new adsorbent for solid phase extraction of cobalt and nickel and determination by flame atomic absorption spectrometry," Talanta, vol. 81, no. 3, pp. 773-777, 2010.

[245] R. S. Praveen, S. Daniel, T. P. Rao, S. Sampath, and K. S. Rao, "Flow injection on-line solid phase extractive preconcentration of palladium(II) in dust and rock samples using exfoliated graphite packed microcolumns and determination by flame atomic absorption spectrometry," Talanta, vol. 70, no. 2, pp. 437-443, 2006.

[246] R. S. Praveen, S. Daniel, and T. P. Rao, "Online flow injection preconcentration and flame atomic absorption spectrometric determination of palladium(II) using inorganic and inorganic-organic hybrid materials-packed microcolumns," Analytical Letters, vol. 39, no. 6, pp. 1187-1199, 2006.
[247] K. Pyrzynska, "Sorption of Cd(II) onto carbon-based materials-a comparative study," Microchimica Acta, vol. 169, no. 1, pp. 7-13, 2010.

[248] F. Sabermahani and M. A. Taher, "Application of a new watersoluble polyethylenimine polymer sorbent for simultaneous separation and preconcentration of trace amounts of copper and manganese and their determination by atomic absorption spectrophotometry," Analytica Chimica Acta, vol. 565, no. 2, pp. 152-156, 2006.

[249] F. Sabermahani and M. Ali Taher, "Determination of trace amounts of cadmium and copper by atomic absorption spectrometry after simultaneous extraction and preconcentration using a new water-soluble polyacrylic acid/alumina sorbent," Microchimica Acta, vol. 159, no. 1-2, pp. 117-123, 2007.

[250] B. F. Senkal, M. Ince, E. Yavuz, and M. Yaman, "The synthesis of new polymeric sorbent and its application in preconcentration of cadmium and lead in water samples," Talanta, vol. 72, no. 3, pp. 962-967, 2007.

[251] A. M. H. Shabani, S. Dadfarnia, T. Moosavinejad, and S. H. Ahmadi, "On-line preconcentration system using a microcolumn packed with Alizarin Red S-modified alumina for zinc determination by flame atomic absorption spectrometry," Quimica Nova, vol. 32, no. 5, pp. 1202-1205, 2009.

[252] Ş. Tokalığlu, V. YIlmaz, Ş. Kartal, A. Delibaş, and C. Soykan, "Solid phase extraction of $\mathrm{Pd}(\mathrm{II})$ on a newly synthesized chelating resin prior to determination by flame atomic absorption spectrometry," Microchimica Acta, vol. 165, no. 34, pp. 347-352, 2009.

[253] G. Xiang, Y. Huang, and Y. Luo, "Solid phase extraction of trace cadmium and lead in food samples using modified peanut shell prior to determination by flame atomic absorption spectrometry," Microchimica Acta, vol. 165, no. 1-2, pp. 237-242, 2009.

[254] S. L. Zhao, H. Yan, H. D. Liang, Z. Z. Yan, and Y. Q. Lin, "PAN-doped $\mathrm{SiO}_{2}$ as a new packing material for the online preconcentration and determination of trace lead (II) in biological and environmental samples using flame atomic absorption," Spectroscopy Letters, vol. 43, no. 2, pp. 122-129, 2010.

[255] Q. X. Zhou, X. N. Zhao, and J. P. Xiao, "Preconcentration of nickel and cadmium by $\mathrm{TiO}_{2}$ nanotubes as solid-phase extraction adsorbents coupled with flame atomic absorption spectrometry," Talanta, vol. 77, no. 5, pp. 1774-1777, 2009.

[256] M. Soylak and M. Tuzen, "Coprecipitation of gold(III), palladium(II) and lead(II) for their flame atomic absorption spectrometric determinations," Journal of Hazardous Materials, vol. 152, no. 2, pp. 656-661, 2008.

[257] C. Duran, D. Ozdes, D. Sahin, V. N. Bulut, A. Gundogdu, and M. Soylak, "Preconcentration of $\mathrm{Cd}(\mathrm{II})$ and $\mathrm{Cu}(\mathrm{II})$ ions by coprecipitation without any carrier element in some food and water samples," Microchemical Journal, vol. 98, no. 2, pp. 317-322, 2011.

[258] I. Schrijver, M. Aramendia, L. Vincze, M. Resano, A. Dumoulin, and F. Vanhaecke, "Comparison of atomic absorption, mass and X-ray spectrometry techniques using dissolution-based and solid sampling methods for the determination of silver in polymeric samples," Spectrochimica Acta, vol. 62, no. 11, pp. 1185-1194, 2007.

[259] A. N. Anthemidis, "Automatic sequential injection liquidliquid micro-extraction system for on-line flame atomic absorption spectrometric determination of trace metal in water samples," Talanta, vol. 77, no. 2, pp. 541-545, 2008.

[260] P. Matúš and J. Kubová, "Complexation efficiency of differently fixed 8-hydroxyquinoline and salicylic acid ligand 
groups for labile aluminium species determination in soilscomparison of two methods," Analytica Chimica Acta, vol. 573-574, pp. 474-481, 2006.

[261] P. Pohl and B. Prusisz, "Application of tandem column solid phase extraction and flame atomic absorption spectrometry for the determination of inorganic and organically bound forms of iron in wine," Talanta, vol. 77, no. 5, pp. 1732-1738, 2009.

[262] C. K. Christou and A. N. Anthemidis, "Flow injection online displacement/solid phase extraction system coupled with flame atomic absorption spectrometry for selective trace silver determination in water samples," Talanta, vol. 78, no. 1, pp. 144-149, 2009.

[263] I. S. I. Adam and A. N. Anthemidis, "Flow injection wetting-film extraction system for flame atomic absorption spectrometric determination of cadmium in environmental waters," Talanta, vol. 77, no. 3, pp. 1160-1164, 2009.

[264] S. Z. Mohammadi, D. Afzali, and Y. M. Baghelani, "Ligandless-dispersive liquid-liquid microextraction of trace amount of copper ions," Analytica Chimica Acta, vol. 653, no. 2, pp. 173-177, 2009.

[265] M. A. Farajzadeh, M. Bahram, B. G. Mehr, and J. A. Jönsson, "Optimization of dispersive liquid-liquid microextraction of copper (II) by atomic absorption spectrometry as its oxinate chelate: Application to determination of copper in different water samples," Talanta, vol. 75, no. 3, pp. 832-840, 2008.

[266] A. N. Anthemidis and K. G. Ioannou, "On-line sequential injection dispersive liquid-liquid microextraction system for flame atomic absorption spectrometric determination of copper and lead in water samples," Talanta, vol. 79, no. 1, pp. 86-91, 2009.

[267] S. Tokalioğlu and A. Livkebabci, "A new solid-phase extraction method for the determination of $\mathrm{Cu}$ (II) and $\mathrm{Fe}$ (III) in various samples by flame atomic absorption spectrometry using N-benzoyl-N-phenylhydroxylamine," Microchimica Acta, vol. 164, no. 3-4, pp. 471-477, 2009.

[268] M. Knap, K. Kilian, and K. Pyrzynska, "On-line enrichment system for manganese determination in water samples using FAAS," Talanta, vol. 71, no. 1, pp. 406-410, 2007.

[269] S. Tokalioğlu, T. Oymak, and Ş. Kartal, "Coprecipitation of lead and cadmium using copper(II) mercaptobenzothiazole prior to flame atomic absorption spectrometric determination," Microchimica Acta, vol. 159, no. 1-2, pp. 133-139, 2007.

[270] S. Jafarvand, A. Bidari, P. Hemmatkhah, M. R. M. Hosseini, and Y. Assadi, "Dispersive liquid-liquid microextraction of silver prior to determination by microsample introductionflame atomic absorption spectrometry," Analytical Letters, vol. 42, no. 14, pp. 2214-2231, 2009.

[271] S. Saracoglu, M. Soylak, D. S. K. Peker et al., "A preconcentration procedure using coprecipitation for determination of lead and iron in several samples using flame atomic absorption spectrometry," Analytica Chimica Acta, vol. 575, no. 1, pp. 133-137, 2006.

[272] F. Xie, X. Lin, X. Wu, and Z. Xie, "Solid phase extraction of lead (II), copper (II), cadmium (II) and nickel (II) using gallic acid-modified silica gel prior to determination by flame atomic absorption spectrometry," Talanta, vol. 74, no. 4, pp. 836-843, 2008.

[273] N. Pourreza and K. Ghanemi, "Determination of copper by flame atomic absorption spectrometry after solid-phase extraction," Spectroscopy Letters, vol. 39, no. 2, pp. 127-134, 2006.

[274] V. N. Bulut, C. Duran, A. Gundogdu, M. Soylak, N. Yildirim, and L. Elci, "A new approach to separation and pre-conce- ntration of some trace metals with co-precipitation method using a triazole," Talanta, vol. 76, no. 2, pp. 469-474, 2008.

[275] K. Suvardhan, K. S. Kumar, D. Rekha, B. Jayaraj, G. K. Naidu, and P. Chiranjeevi, "Preconcentration and solidphase extraction of beryllium, lead, nickel, and bismuth from various water samples using 2-propylpiperidine-1-carbodithioate with flame atomic absorption spectrometry (FAAS)," Talanta, vol. 68, no. 3, pp. 735-740, 2006. 


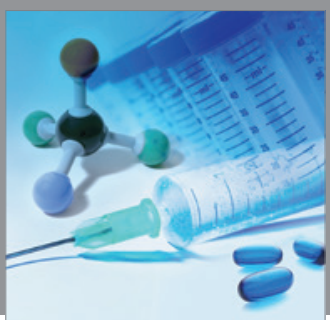

International Journal of

Medicinal Chemistry

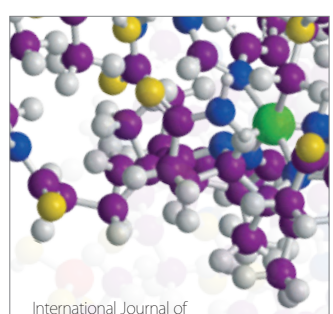

Carbohydrate Chemistry

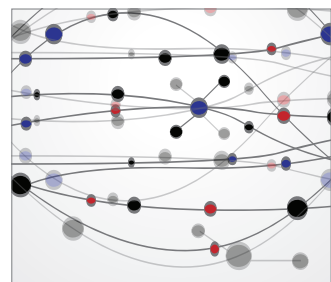

The Scientific World Journal
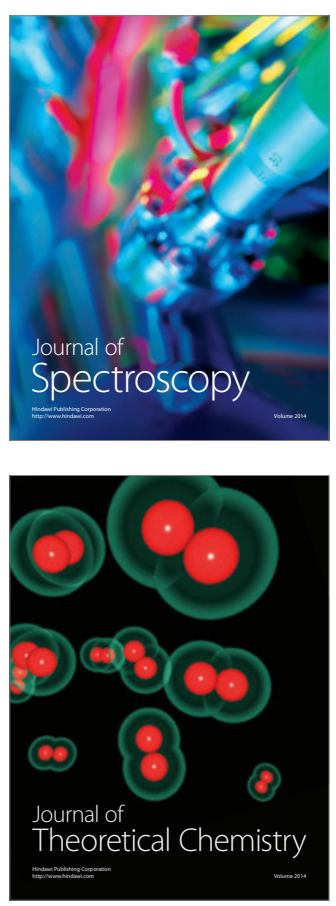
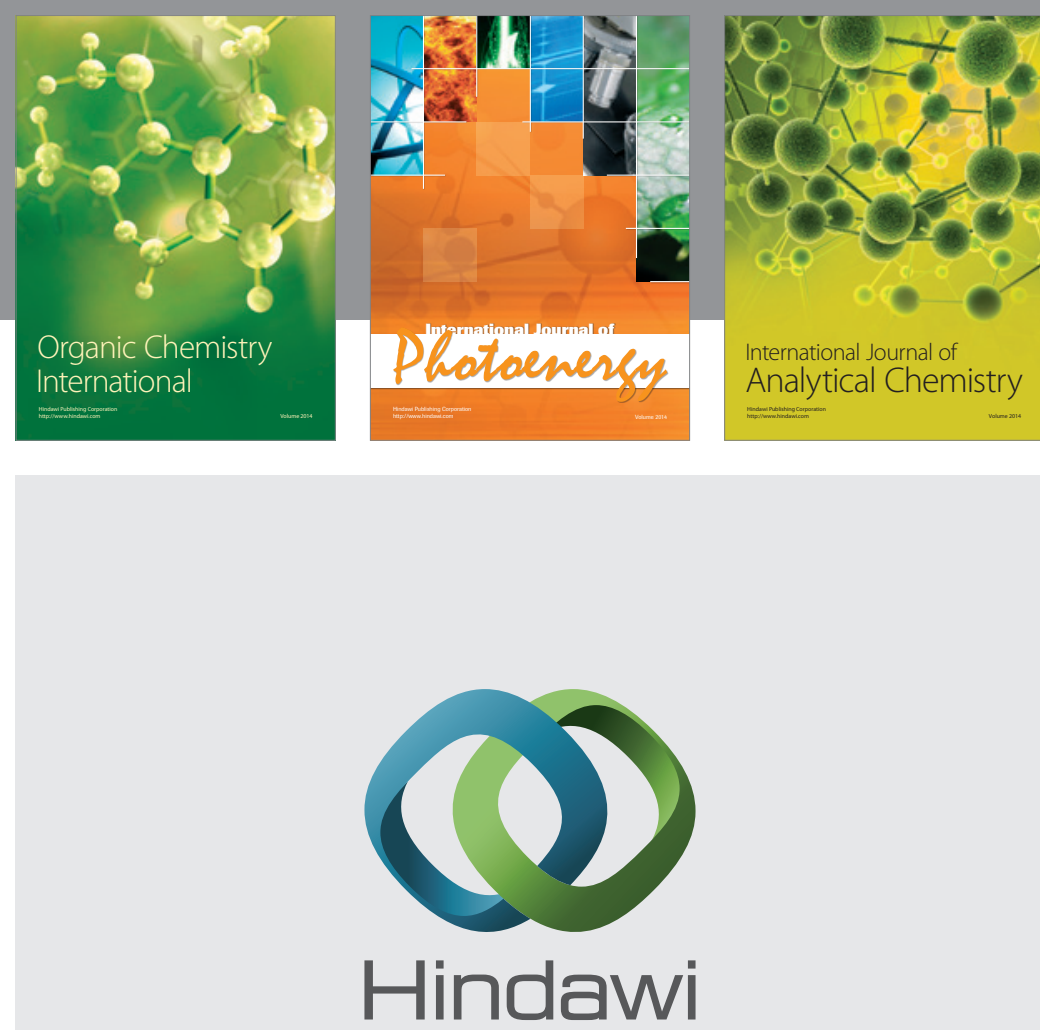

Submit your manuscripts at

http://www.hindawi.com
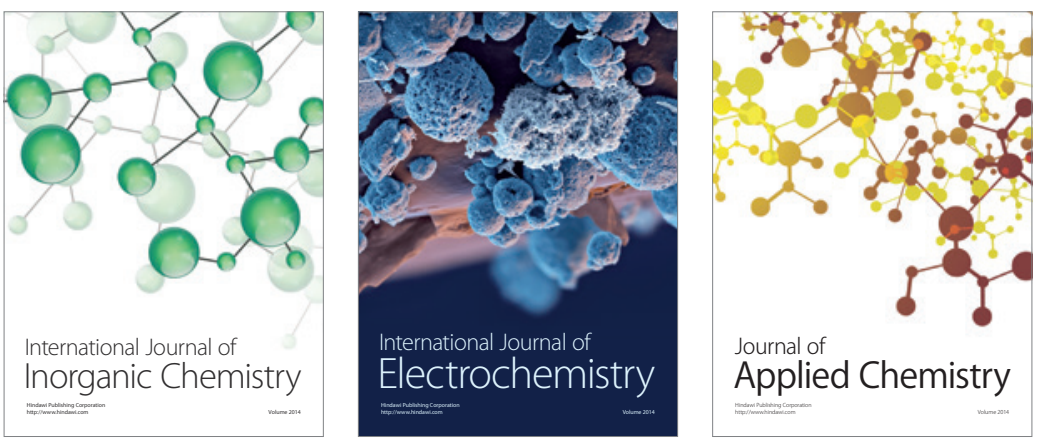

Journal of

Applied Chemistry
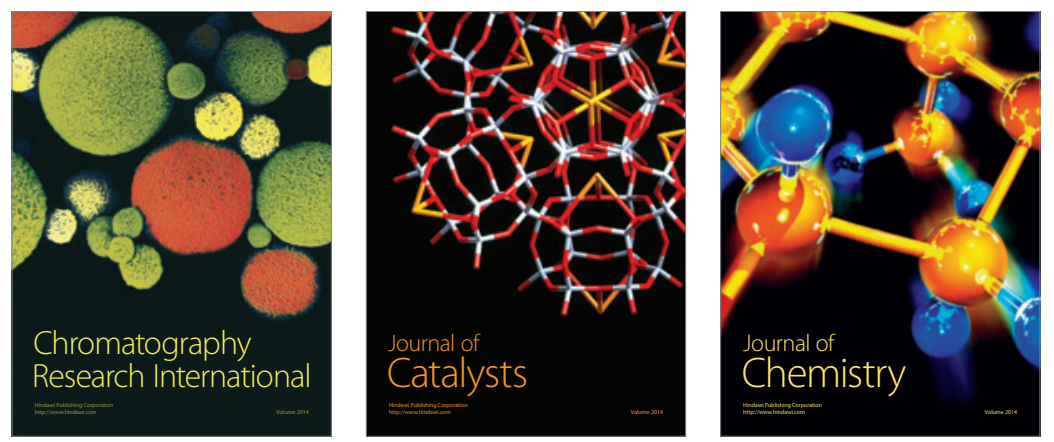
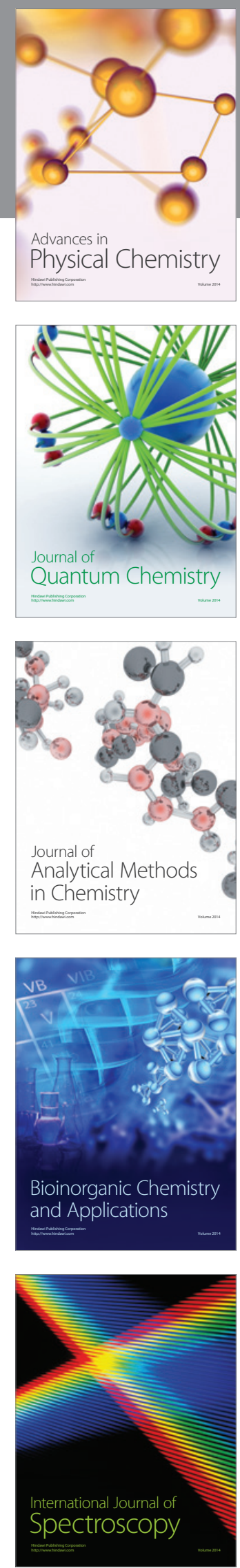